\title{
Towards a consistent design approach for steel joints under generalized loading
}

\author{
L. Simões da Silva* \\ ISISE, Civil Engineering Department, Universidade de Coimbra, Coimbra, Portugal
}

\begin{abstract}
The behaviour of steel joints is complex and requires the proper consideration of a multitude of phenomena, ranging from material non-linearity (plasticity, strain-hardening), non-linear contact and slip, geometrical non-linearity (local instability) to residual stress conditions, and complicated geometrical configurations. The component method is widely accepted as the practical approach in predicting the behaviour of steel joints and it provides detailed procedures to evaluate the strength and initial stiffness of steel joints, as specified in Eurocode 3.

Current safety concerns for steel structures require that steel joints are designed to perform adequately under a wider range of loading conditions: besides standard static loading conditions, fire and seismic loading must often be considered. In addition, robustness requirements impose that joints present a minimum level of resistance for any arbitrary loading. Predicting the 3-D behaviour of steel joints under arbitrary loading must thus be achieved in a practical way.

This paper presents the results of a series of experimental developments that attempt to contribute to the knowledge of the 3D behaviour of steel joints, under static and dynamic conditions, and to discuss a possible framework for these general conditions that is in line with the principles of the component method.
\end{abstract}

(C) 2008 Elsevier Ltd. All rights reserved.

Keywords: Steel structures; Connections; Component method; Eurocodes; 3D-behaviour

\section{Introduction}

The analysis of the behaviour of steel joints is very complex and requires the proper consideration of a multitude of phenomena, ranging from material non-linearity (plasticity, strain-hardening), non-linear contact and slip, geometrical non-linearity (local instability) to residual stress conditions, and complicated geometrical configurations [47]. Fig. 1(a) illustrates a typical non-linear moment-rotation curve $\left(M_{j}-\phi\right)$. For simplicity, it is usual to define an idealized moment-rotation curve (Fig. 1(b)) and three fundamental properties: stiffness $\left(S_{j}\right)$ and, in particular, initial stiffness $\left(S_{j, \text { ini }}\right)$, moment resistance $\left(M_{j, R d}\right)$ and rotation capacity $\left(\phi_{C d}\right)$.

A considerable effort has thus been undertaken since the early 1970's to give consistent predictions for the behaviour of steel joints. Initially, most research studies on the behaviour

\footnotetext{
* Corresponding address: Departamento de Engenharia Civil, Universidade de Coimbra, Polo 2 da Universidade, Rua Luís Reis Santos, P-3030-788 Coimbra, Portugal. Tel.: +351 239 797216; fax: +351 239797217 .

E-mail address: luisss@dec.uc.pt.
}

of semi-rigid joints were focused on determining resistance and stiffness characteristics $[60,16,58]$, leading, for example, to the code specifications for the evaluation of strength and stiffness of steel joints that were prepared for Eurocode 3 [4]. More recently, emphasis has shifted towards the evaluation of the ductility of steel joints [43], in order to validate the partial strength design of unbraced steel frames.

Although numerical approaches using non-linear finite elements could deal with all the complexities of joint behaviour, they require lengthy procedures and are very sensitive to the modelling and analysis options. The Eurocode 3 design approach consists of the so-called component method that supplies procedures for the evaluation of the rotational behaviour of joints, thus allowing the specification of the corresponding moment-rotation curve or the associated properties. It corresponds to a simplified mechanical model composed of extensional springs and rigid links, whereby the joint is simulated by an appropriate choice of rigid and flexible components. These components represent a specific part of a joint that, dependent on the type of loading, make an identified contribution to one or more of its structural properties [58], 


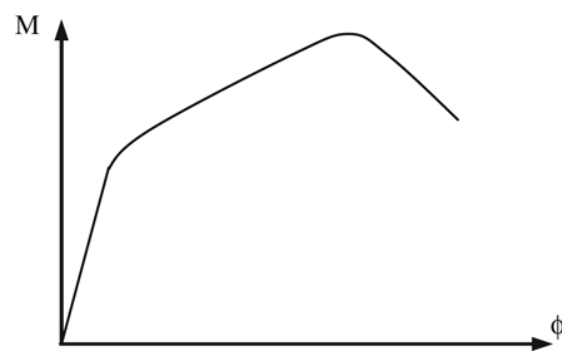

(a) Real moment-rotation curve.

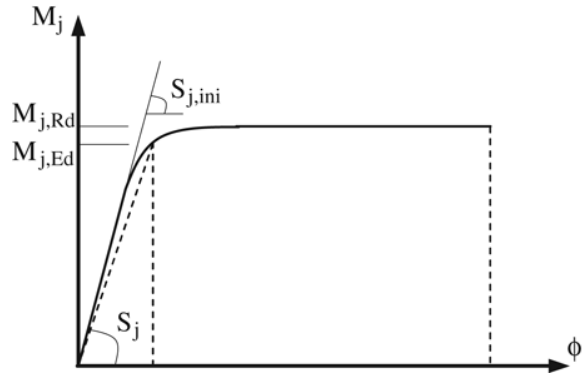

(b) Idealized moment-rotation curve.

Fig. 1. Joint moment-rotation curve.

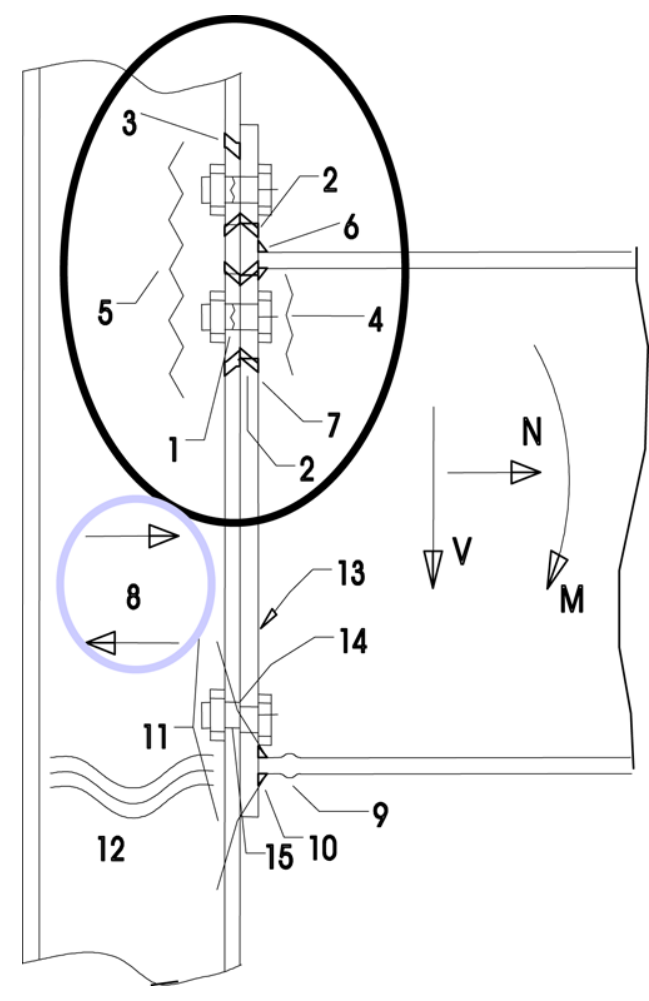

Fig. 2. Typical beam-to-column components.

as illustrated in Fig. 2. Typical examples of components for bolted steel joints are (i) column web panel in shear, (ii) endplate in bending, (iii) column flange in bending, (iv) beam web in tension, (v) column web in compression, (vi) column web in tension, (vii) beam flange and web in compression, (viii) bolts in tension and (ix) welds. In general, each of these components is characterized by a non-linear force-deformation curve, although simpler idealizations are possible.

Obviously, given the complexity of steel joints, the development of the component method, and the prediction of the behaviour of steel joints in general, heavily relied on the results of a large number of experimental research programmes carried out at a number of research institutes [7]. Consequently, the component method provides good predictions of the non-linear behaviour of moment-resisting steel joints when subjected to monotonic loading.

Steel joints exhibit a behaviour that ranges from very rigid to extremely flexible. Obviously, the deformability of joints varies in accordance with the applied loading: a joint may
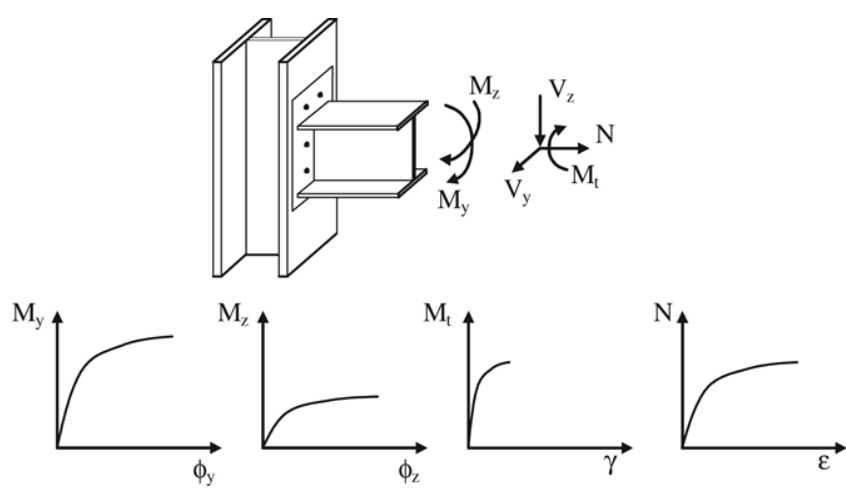

Fig. 3. Typical 3D behaviour of bolted end-plate beam-to-column steel joint.

behave very rigidly when subjected to shear force or torsion but show a flexible response when subjected to bending. Fig. 3 illustrates this statement for a typical bolted end-plate beam-tocolumn steel joint: rigid in torsion or shear, semi-rigid under major axis bending or axial force and flexible under minor axis bending [52].

The corresponding moment (force)-rotation (displacement) curves are clearly non-linear, a typical feature of joint behaviour. The incorporation of joint behaviour into the structural analysis is thus more complex.

In general terms, a steel connection can be modelled as a six degree-of-freedom non-linear spring. This representation is adequate whenever the behaviour of the connection can be uncoupled into six independent internal forces (two bending moments, a torsional moment, an axial force and two shear forces). This assumption is not always adequate, in which case the consideration of interaction formulae becomes necessary. The $M-N$ interaction is a typical example [50,5].

Deformability in bending is usually critical and mostly influences the results from structural analysis [52]. Normally, the deformability corresponding to the remaining degrees of freedom is either much lower, or the global behaviour of the structure does not induce significant internal forces in the other directions (as it is the case, for example, of the resistance of a beam-to-column connection around the beam minor axis). In this case, the corresponding degrees of freedom can be safely modelled with either infinite or zero stiffness. However, the recent concern on the robustness of structures [48] where joints play a major role, together with accidental loading cases such as seismic or fire events completely changed this picture. Designers are now faced with a stronger need to predict the $3 \mathrm{D}$ 

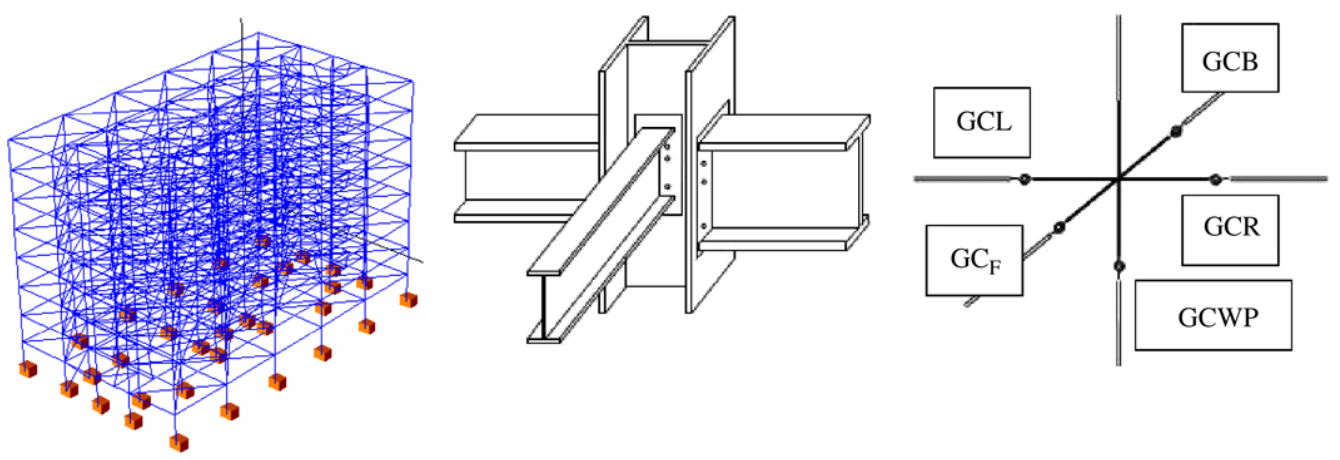

Fig. 4. (a) Structural model; (b) Detail of internal node (c) generalized joint element.

behaviour of a structure and, consequently, the 3D behaviour of the joints.

It is the objective of this paper to present some experimental developments that attempt to contribute to the knowledge of the 3D behaviour of steel joints, under static and dynamic conditions, and to discuss a possible framework for these general conditions that is in line with the principles of the component method.

\section{Conceptual design model for 3D joint behaviour under generalized loading}

Experimental tests and observations of real structures have shown that, for certain loading conditions, joints behave fully in 3D. This is clearly what happens under fire conditions. In addition, robustness requirements also demand a minimum level of resistance for any arbitrary loading.

The implementation of a practical yet consistent approach to predict the 3D behaviour of steel joints should satisfy the following requirements:

- adoption of the principles of the component method;

- seamless integration within global 3D structural models.

The first requirement ensures a realistic estimate of the behaviour of steel joints that is compatible with practical design, while the second requirement means that a consistent and unified analysis-design model can be achieved [52].

Starting from the global viewpoint, the incorporation of the real behaviour of the connections in the structural model (Fig. 4(a)) can only be achieved in a practical way with the implementation of a generalized joint element (GJ). This joint element should be assigned to all structural nodes, with the relevant degrees-of-freedom. However, given the actual detailing of the connections, a standard six degrees-of-freedom ( 3 translations and 3 rotations) joint element is not adequate.

Fig. 4(b) illustrates a typical nodal configuration for a Hshaped column. The fact that several members converge to the same node, but connected to different parts of the column cross-section (flanges or web), means that the generalized joint element must be composed of several generalized connections (GC) and a generalized column web panel (GCWP), with appropriate eccentricities, as illustrated in Fig. 4(c). In the most general case of an internal column where four beams converge, the generalized joint element comprises the following sub-elements:

$G J=\left[\begin{array}{ccccc}G C_{R}^{M J} & 0 & 0 & 0 & 0 \\ 0 & G C_{L}^{M J} & 0 & 0 & 0 \\ 0 & 0 & G C W P & 0 & 0 \\ 0 & 0 & 0 & G C_{F}^{M I} & 0 \\ 0 & 0 & 0 & 0 & G C_{B}^{M I}\end{array}\right]$.

Each generalized connection element and the generalized column web panel element contains the appropriate degreesof-freedom. The structure of the stiffness matrix for the generalized connection element for a major axis beam is illustrated in expression (2) and contains the usual 3D six degrees-of-freedom. It is a semi-diagonal matrix because of the strong $M-N$ and the shear and torsion interactions.

$\begin{gathered}N \\ M_{y} \\ M_{z} \\ V_{y} \\ V_{z} \\ T\end{gathered}\left[\begin{array}{cccccc}a_{11} & a_{12} & 0 & 0 & 0 & 0 \\ a_{21} & a_{22} & 0 & 0 & 0 & 0 \\ 0 & 0 & a_{33} & 0 & 0 & 0 \\ 0 & 0 & 0 & a_{44} & a_{45} & a_{46} \\ 0 & 0 & 0 & a_{54} & a_{55} & a_{56} \\ 0 & 0 & 0 & a_{64} & a_{65} & a_{66}\end{array}\right]$.

A possible structure for the stiffness matrix of the generalized column web panel element is illustrated in expression (3) and comprises three degrees-of-freedom: in-plane rotation, out-ofplane rotation and vertical displacement. It is a diagonal matrix, the interactions between the three generalized deformations being implemented as modifying factors within each individual stiffness coefficient, where relevant.

$$
\begin{gathered}
N_{b}^{M J}+M_{b}^{M J} \\
M_{b}^{M I} \\
V_{b}^{M I}
\end{gathered}\left[\begin{array}{ccc}
b_{11} & 0 & 0 \\
0 & b_{22} & 0 \\
0 & 0 & b_{33}
\end{array}\right] .
$$

Finally, the generalized connection element for a minor axis beam is illustrated in expression (4) and contains two degreesof-freedom: rotation and vertical displacement.

$M_{b}^{M I}$
$V_{b}^{M I}$$\left[\begin{array}{cc}c_{11} & 0 \\ 0 & c_{22}\end{array}\right]$

The total number of generalized degrees-of-freedom is thus 19 for the most general configuration (4 beams).

Each generalized stiffness coefficient, $a_{11}$ to $c_{22}$, must correspond to the condensation of the appropriate component 


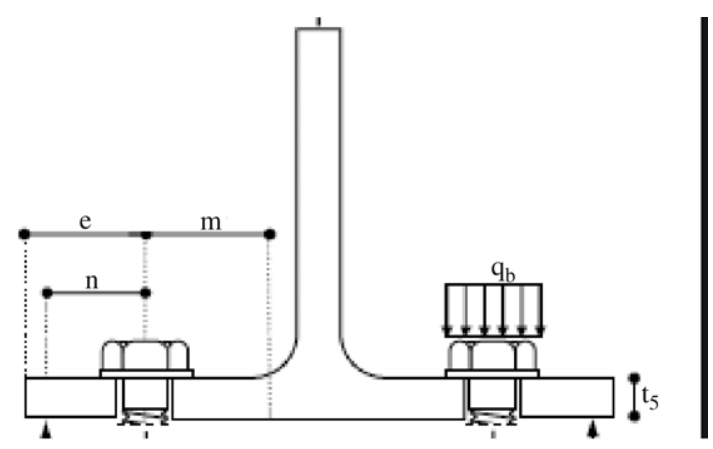

Fig. 5. T-Stub in transverse bending.

model. For example, for an end-plate beam-to-column minor axis connection, $c_{11}$ corresponds exactly to the assembly of the relevant components for this case currently available in part 1-8 of Eurocode 3. However, other generalized stiffness coefficients require newly developed components, such as $a_{33}$, that require the characterization of a T-Stub in transverse bending, schematically illustrated in Fig. 5.

Another example of generalized stiffness coefficients requiring extension of current procedures are, for example, $b_{11}$ and $b_{22}$, corresponding, respectively, to the column web panel under generalized in-plane loading (incorporating the column web in compression, column web in tension and column web in shear) and the column web panel in transverse bending.

\section{Extending knowledge at the component level}

\subsection{Introduction}

The analysis and design of joints in the framework of the component method requires the knowledge of the behaviour of all relevant components. Currently, part 1-8 of Eurocode 3 [4] specifies strength and stiffness properties for 21 different components that allow the calculation of a wide range of beamto-column, beam-to-beam and column base joint typologies.
However, in order to deal with generalized loading conditions (3D joints or combined loading), either new additional components need to be considered, or the range of validity of some of the components must be extended. In the following, the results of three experimental research projects carried out at the University of Coimbra aimed at characterizing new components or improving/enlarging the range of applicability of existing components are briefly presented.

\subsection{Column web in bending}

In the case of minor axis joints (Fig. 6(a)), part 1-8 of Eurocode 3 limits the application of the component method to internal nodes with symmetrical loading. This is a particular case where no bending moment is transmitted to the column through its web, that therefore does not contribute to the joint deformation, similarly to a beam splice response. However, if the moments from both sides of the column are unequal, the column web is deformed transversally in bending as represented in Fig. 6(b). This is also the case of an I-beam connected to the face of a RHS column, also similar to the column web behaviour in a minor axis joint (Fig. 7). Finally, in the case of a 3D node where both major and minor axis connections converge, the interaction between in-plane forces and out-of-plane bending of the column web must be considered.

Historically, the study of the behaviour of minor axis joints can be traced back to Young and Jackson in 1934 [59]. Since the 1980's, the experimental works of Rentschler, Chen and Driscoll [37], Chen and Lui [6], Janss et al. [15], Jaspart [16], Gomes et al. [14], Davison et al. [8], Kim [23] and Maquoi et al. [30] provided clear evidence of the crucial contribution of the column web panel out-of-plane deformation to the joint response and highlighted its plate-like behaviour and the significant membrane effects resulting from large flexural displacements. This typical behaviour is illustrated in Fig. 8(a).

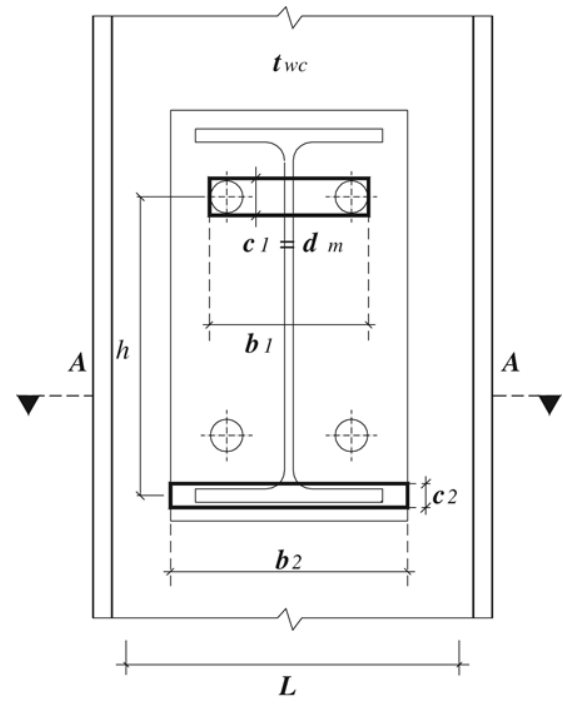

(a) Joint geometry and dimensions.

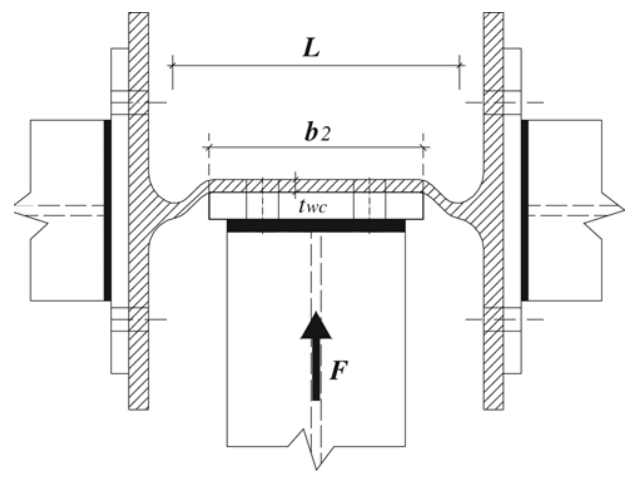

(b) Column web deformed in bending.

Fig. 6. Minor axis beam-to-column joints [33]. 


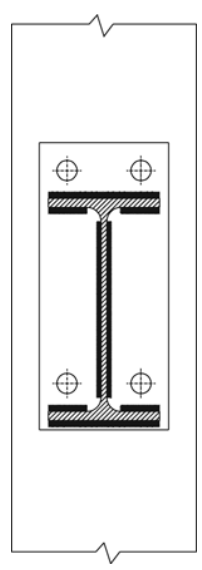

(a) Conf. (1).

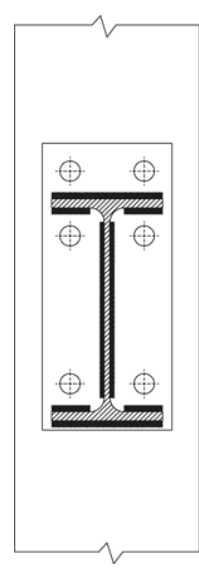

(b) Conf. (2).

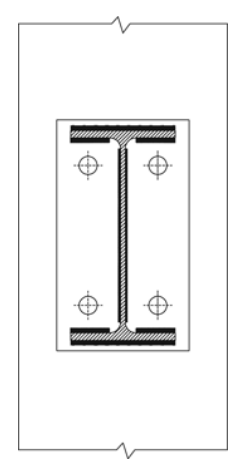

(c) Conf. (3).
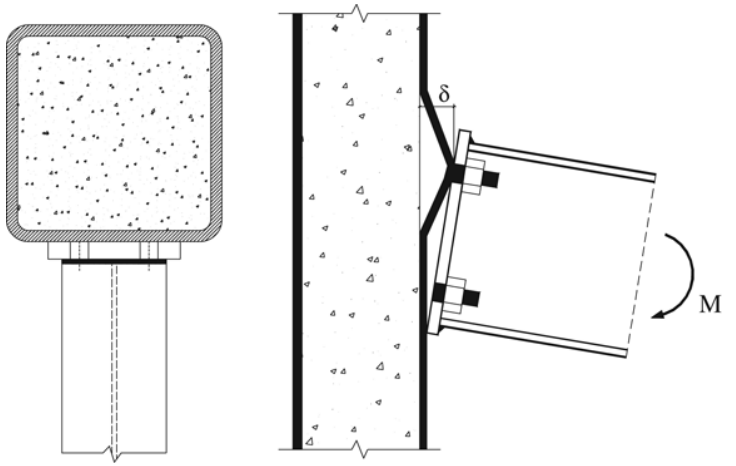

Column face deformed in bending.

Fig. 7. I-beam to concrete-filled RHS column joints [34].

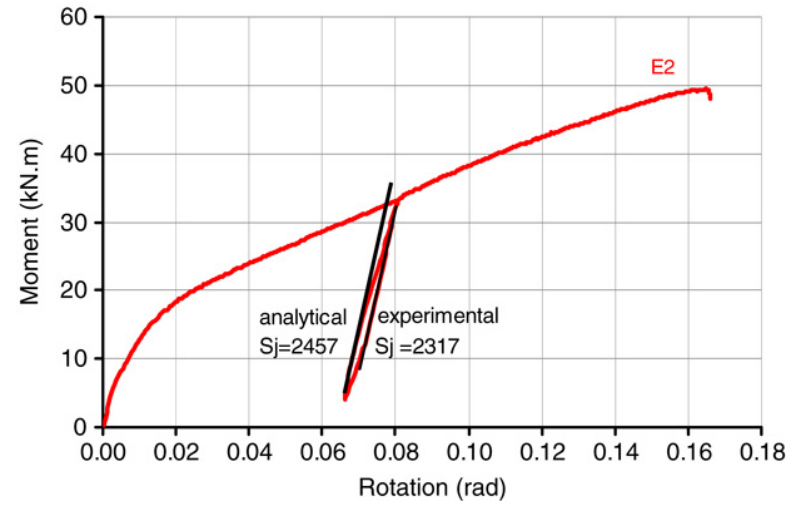

(a) Application to a minor axis joint (E2 in [33]).

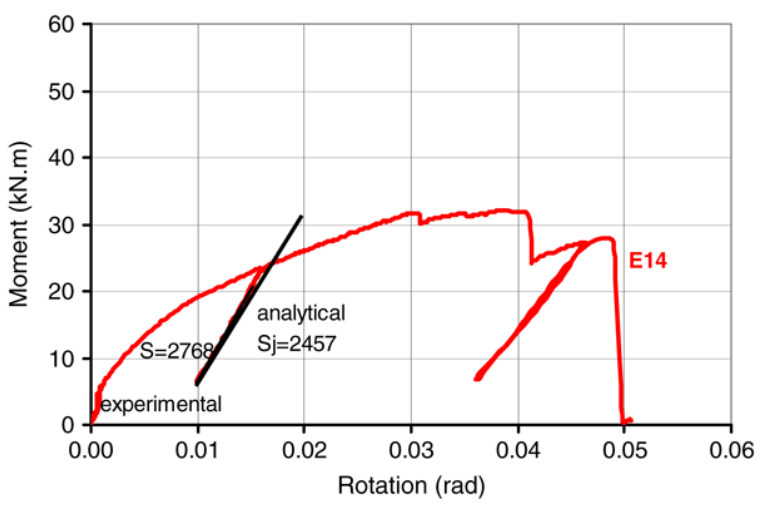

(b) Application to a RHS joint (E14 in [34]).

Fig. 8. Application of the model to experimental results, example of minor axis and RHS joints [35].

Similarly, bolted end-plate I-beam to RHS column joints have been studied by several authors: $[9,11,24,28,29,31,33$, $34,49,55]$. Identical results were obtained, as illustrated in Fig. 8(b).

More recently, an experimental testing program was carried out at the University of Coimbra comprising a series of 14 tests for both configurations described in Figs. 6 and 7. Details of the testing program and instrumentation may be found in [33, 34], respectively, for minor axis or for RHS joints. The adopted instrumentation enabled the characterization of the component column web in transverse bending, including the derivation of the stress distribution, deformation pattern of the component and the measurement of the forces at each bolt row.

These studies confirmed that this component behaves, in the elastic range, essentially in the direction between the flanges or the lateral faces. As an illustration for a minor axis joint, Fig. 9 shows test strain results from locations at points 3 to 9 . It was concluded from the moment-strain curves that the higher stresses are in the line with the uppermost bolt row, and they decrease with the vertical distance from this line. In addition, the stress measured in the perpendicular direction (no. 7) is quite small, demonstrating the behaviour as a strip spanning in one direction.
Similar results for a RHS column were obtained. It could be concluded that until generalized yielding is attained it is possible to assume an elastic distribution of stresses and, consequently, elastic forces in the stud rows. In addition, principal directions are very close to the vertical and to the horizontal axis, with low stresses in the vertical direction, confirming the one-dimensional strip behaviour [35].

The moment-rotation curves of Fig. 9 highlighted the difficulty in establishing a design moment resistance for minor axis joints, given that, for thinner webs, a gentle loss of stiffness is observed as the column web starts to yield. Several authors developed yield-line mechanisms that attempt to establish a plastic moment resistance for the column web $[36,14]$. The Gomes model was later used by Neves [32] to statistically calibrate expressions for the post-limit stiffness (accounting for membrane effects), based on finite element numerical simulations. Finally, the experimental results reported above allowed the calibration of the analytical model illustrated in Fig. 10 for the prediction of the stiffness of this component based on a strip model, full details being available in [35].

These developments concerning the behaviour of the column web panel subjected to transverse bending should allow the establishment of the stiffness coefficient $b_{22}$ defined in 

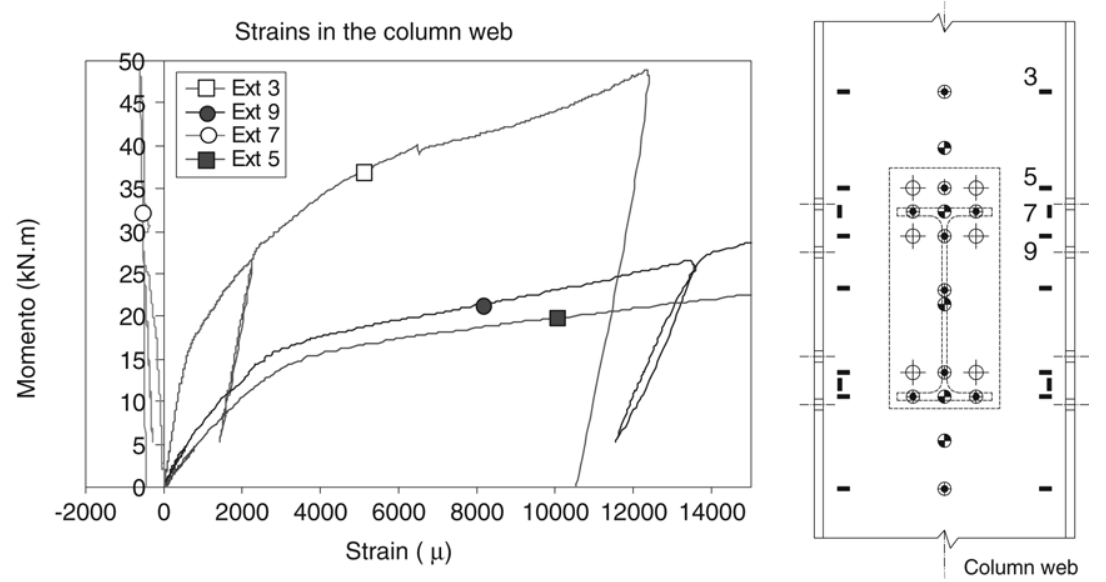

Fig. 9. Steel beam-to-column minor axis joint: experimental strains in the column web (two bolt rows in tension) [35].

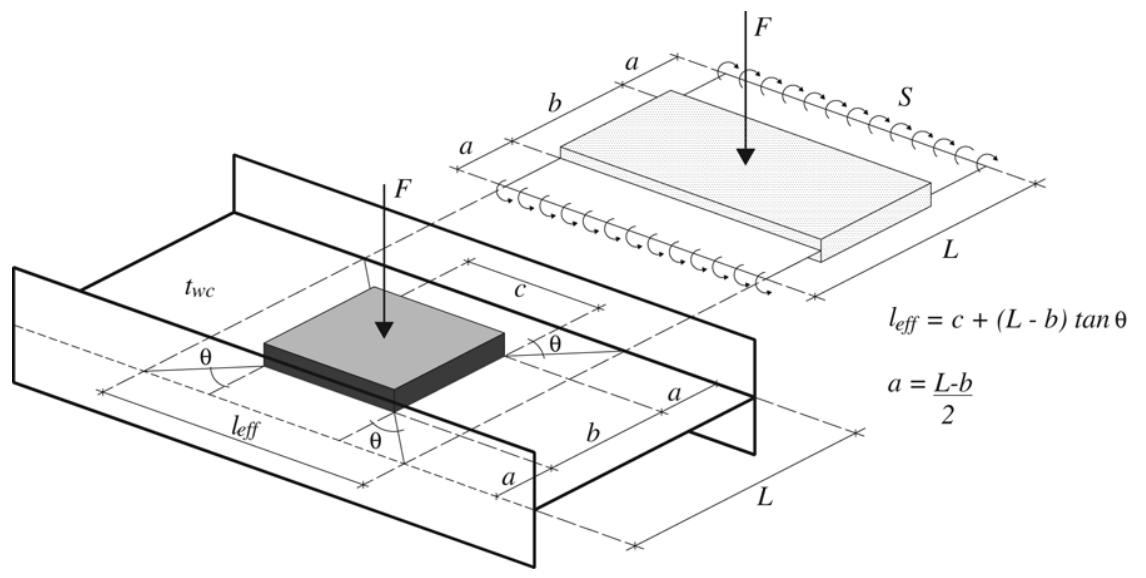

Fig. 10. Strip model for the stiffness of the column web in transverse bending [35].

expression (3). However, some developments are still required to achieve this goal: (i) the incorporation of a simplified largedisplacement formulation including the influence of membrane effects to estimate the post-limit response of the joint; (ii) the establishment of a procedure to deal with a panel connecting beams with different levels of bending moment; and, most importantly (iii) the systematic validation of the procedure for a wide range of cases and experimental results.

\subsection{Column web under generalized in-plane loading}

Internal node joints, when compared to single-sided joint configurations, present the added complexity of having to deal with: (i) left hand side connection deformability $M_{b 1}-\phi_{c 1}$; (ii) right hand side connection deformability $M_{b 2}-\phi_{c 2}$; and (iii) column web panel shear deformability $V_{w p}-\gamma$ [17].

Focusing on the column web panel, it must resist direct tensile and compressive forces resulting from the left and right connections, as well as shear forces whenever the left and right beam moments are different. In the context of the component method, three (almost) uncoupled components are considered: (i) column web in tension, (ii) column web in compression and (iii) column web panel in shear. The column web panel has been extensively studied by several authors [25,16,26]. However, these studies were always carried out in the context of external nodes or internal nodes with beams of similar height. Fig. 11 illustrates the stress contours (normal and shear stresses) and the principal directions obtained using finite element calculations for the following two cases: (i) single-sided welded beam-to-column joint, and (ii) double-sided welded beamto-column joint with beams of unequal height [19]. In the first case, the column web panel presents three relatively independent zones (shear, compression and tension). Due to the fact that the load entering the web panel is no longer aligned on both sides, the stress fields are far more complex for the latter case, and the referred zones are no longer independent. It seems thus clear that current procedures for the design of the web panel require extensions and validation to cover this case.

An experimental test programme was carried out at the University of Coimbra on the behaviour of the column web panel in double-sided welded beam-to-column joints with beams of unequal height. It consists of two series of tests on S355 and S690 steel prototypes. In order to study the column web panel under an arbitrary stress state, a double-sided beamto-column joint with a relation between the heights of the beams of 0.5 (IPE400 and HEB240) was chosen. Five tests on S355 steel grade models and eight tests on S690 steel grade models were performed. The nodes considered were external node, internal node with similar heights and internal nodes with 

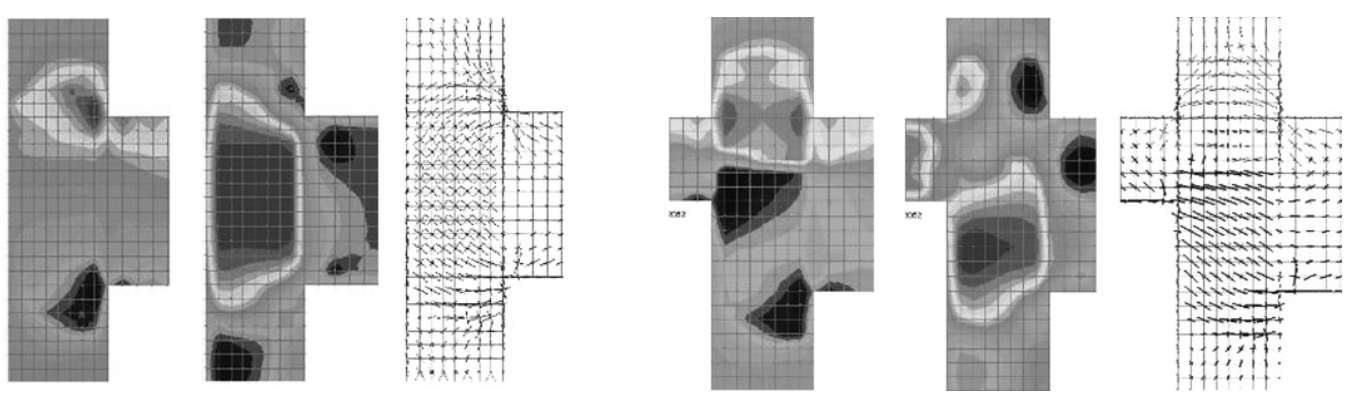

Fig. 11. Stress state in an external node, and an internal node with different beams (normal horizontal stress, shear stress and principal directions).

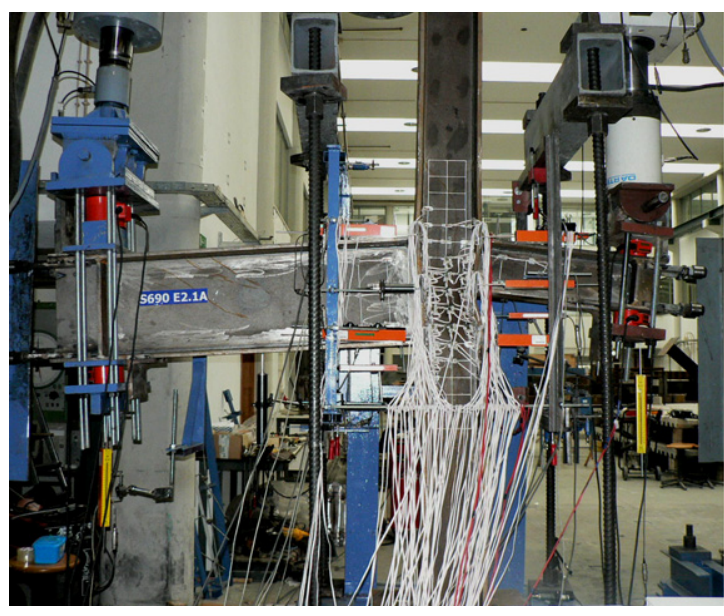

(a) Experimental model after the test.

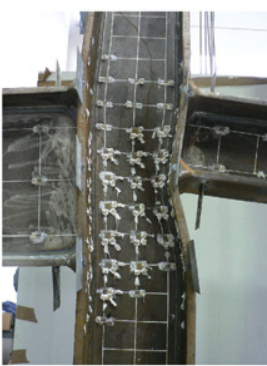

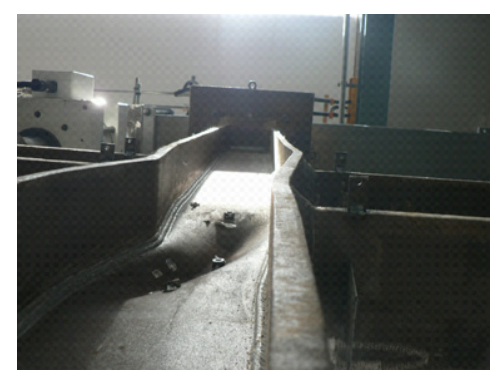

(b) Details of column web panel.

Fig. 12. Internal node with beams of different heights (symmetrical load), steel grade S690 [21].

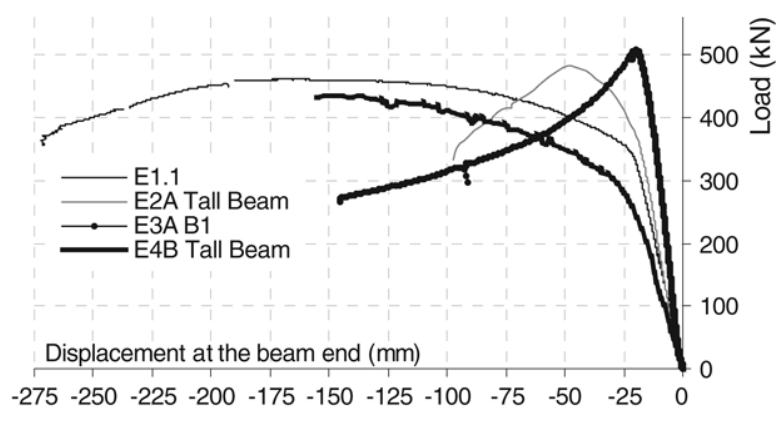

Fig. 13. Comparison between the results of each different node [20].

beams of different heights (symmetrical and anti-symmetrical load). Table 1 summarizes the prototypes and loading strategies used.

Details of the testing program and instrumentation may be found in [20,21], respectively, for S355 and S690 joints. The adopted instrumentation enabled the characterization of the column web panel, including the derivation of stress distributions, deformation patterns of the components. Fig. 12 depicts the results of test E2AH, while Fig. 13 shows a comparison between all curves for $\mathrm{S} 690$ where, for clarity, only the results related to the taller beam are shown.

The Eurocode 3 model for the behaviour of the column web panel subjected to in-plane actions was developed by Jaspart [16] and is based on the Atamaz-Jaspart model that splits the shear behaviour of the panel and the load-introduction effect. For internal nodels with beams of unequal heights, it was shown $[53,22]$ that a modified Atamaz-Jaspart formulation consisting of two shear panels and 3 levels of load introduction yields good results. Fig. 14 compares the experimental results with the application of the model for test E2.

Finally, a simplified approach compatible with the Eurocode 3 design procedure was also developed, consisting of modified $\beta$ values in the framework of the component model illustrated in Fig. 15.

In the context of the generalized stiffness coefficient $b_{11}$, it remains to formulate a new sub-element capable of condensing the various in-plane contributions (shear and load introduction). An interesting development was recently presented by Bayo et al. [1], who formulated a new element to model the column web panel that could be extended to accommodate beams of different heights.

\subsection{Non-linear behaviour of the T-stub in tension}

The T-Stub in tension constitutes an adequate idealization of the tensile zone of end-plate connections, as shown in Fig. 16 in the context of beam-to-column end-plate connections. The TStub concept was developed in the 1970's by Zoetemeijer [60] to idealize the tension region of end plate connections and to propose and validate yield line models for the evaluation 

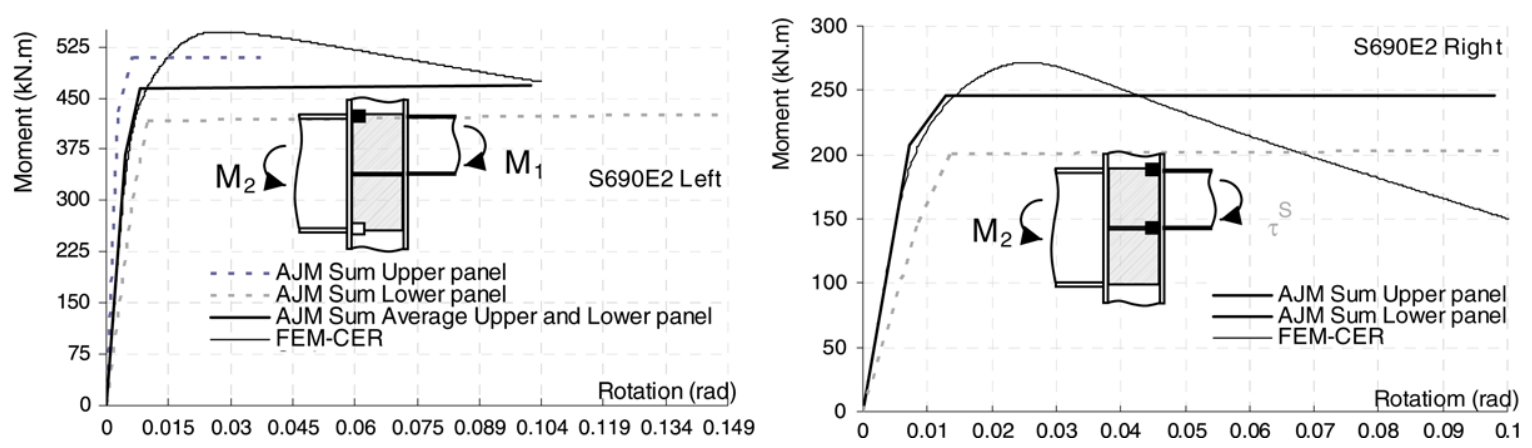

Fig. 14. Comparison between experimental and analytical resuslts [22].

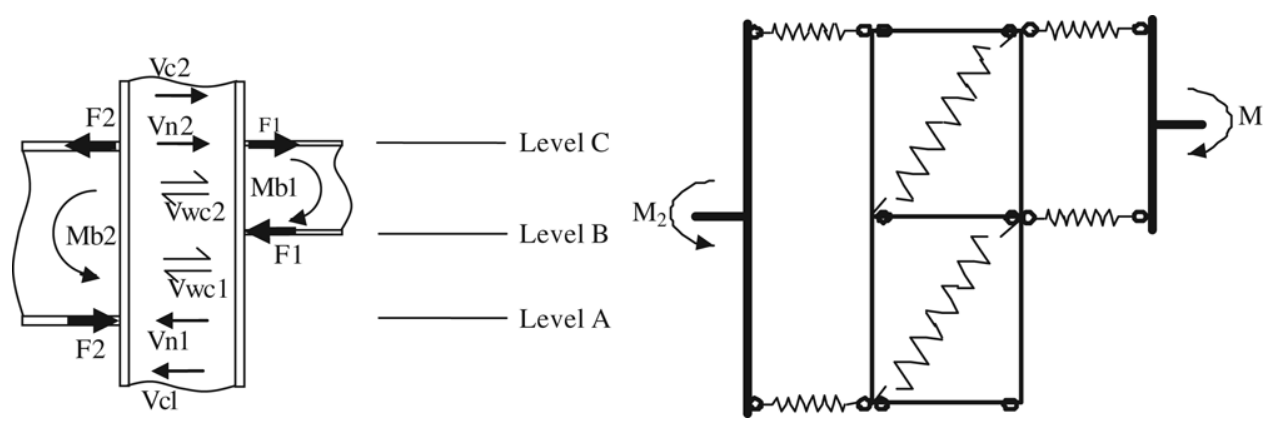

Fig. 15. Simplified design procedure [22].

Table 1

Summary of the experimental tests

\begin{tabular}{|c|c|c|c|c|c|}
\hline Test & Beam 1 & Beam 2 & Column & Grade & Load \\
\hline E1.1 & - & IPE400 & HEB240 & S355 & $M-$ \\
\hline E1.2 & - & IPE400 & HEB240 & S355 & $M-$ \\
\hline E2.1 & HEB200 & IPE400 & HEB240 & S355 & $M-/ M-$ \\
\hline E3.1 & IPE400 & IPE400 & HEB240 & S355 & $M-/ M-$ \\
\hline E4.1 & HEB200 & IPE400 & HEB240 & S355 & $M-/ M+$ \\
\hline E1.1H & - & IPE400 ${ }^{\mathrm{a}}$ & HEB $240^{\mathrm{a}}$ & S690 & $M-$ \\
\hline $\mathrm{E} 1.2 \mathrm{H}$ & - & IPE400 ${ }^{\mathrm{a}}$ & HEB $240^{\mathrm{a}}$ & S690 & $M-$ \\
\hline E2AH & HEB $200^{a}$ & IPE400 ${ }^{\mathrm{a}}$ & HEB $240^{\mathrm{a}}$ & S690 & $M-/ M-$ \\
\hline E2BH & HEB $200^{a}$ & IPE400 ${ }^{\mathrm{a}}$ & HEB $240^{a}$ & S690 & $M-/ M-$ \\
\hline E3AH & IPE400 ${ }^{\mathrm{a}}$ & IPE400 ${ }^{\mathrm{a}}$ & HEB $240^{\mathrm{a}}$ & S690 & $M-/ M-$ \\
\hline E3BH & IPE400 ${ }^{\mathrm{a}}$ & IPE400 & HEB $240^{\mathrm{a}}$ & S690 & $M-/ M-$ \\
\hline $\mathrm{E} 4 \mathrm{AH}$ & HEB $200^{a}$ & IPE400 & HEB $240^{\mathrm{a}}$ & S690 & $M-/ M+$ \\
\hline E4BH & HEB $200^{a}$ & IPE400 ${ }^{\mathrm{a}}$ & HEB $240^{\mathrm{a}}$ & S690 & $M-/ M+$ \\
\hline
\end{tabular}

${ }^{\mathrm{a}}$ Equivalent welded sections.

of strength. It was later also used by Davison et al. [8] and Jaspart [16] to develop predictions of the initial stifness of moment connections. It comprises 3 components: end-plate in bending, bolts in tension and column flange in bending. It is characterized by a complex behaviour resulting from the interplay between ductile and brittle components.

Ductility requirements of partial strength joints led to the need of establishing the full non-linear behaviour of the T-Stub [46]. This evaluation gains even further relevance because of the detrimental effect of the over-strength of steel and the need to extend the knowledge to high strength steels.

A research project on the non-linear behaviour of the T-Stub in tension was carried out at the University of Coimbra, comprising a series of 32 tests on T-stubs [12], 8 tests on extended end-plate moment connections and extensive numerical simulations using nonlinear finite elements. The T-Stub tests comprised normal and high strength steels, unstiffened and stiffened specimens and asymmetrical specimens including a stiffener only on one side of the connection. Fig. 17 illustrates various failure types observed in the experiments (combined bending and tension bolt fracture (type-A), stripping of the nut threads bolt fracture (type-B), cracking of the plate material in the HAZ (type-C) and combined failure modes A and $\mathrm{C}$ (type-AC)).

The T-Stub model of Fig. 18 was proposed, where the bolt behaviour is incorporated by means of an extensional spring located at section (C), i.e. at the bolt vertical axis. The bolt elongation response is reproduced with the trilinear relationship proposed by Swanson [54].

The flange material constitutive law is modelled by means of a piecewise (true) stress-(logarithmic) strain relationship that accounts for the strain hardening effects. It incorporates a reduction of the Young modulus of the flange material, $E_{\text {red, }}$, given by [13]:

$E_{\mathrm{red}}=\frac{E}{3}\left(\frac{m}{t_{f}}\right)^{2}\left[\sqrt{1+\frac{3}{\left(m / t_{f}\right)^{2}}}-1\right]$

that incorporates a statistically calibrated factor that improves the analytical results when compared to the experiments. This reduction also accounts for the influence of the shear deformation of thick flanges in the elastic behaviour. The two possible ultimate (fracture) conditions of the T-stub are: (i) fracture of the bolt and (ii) cracking of material of the flange 


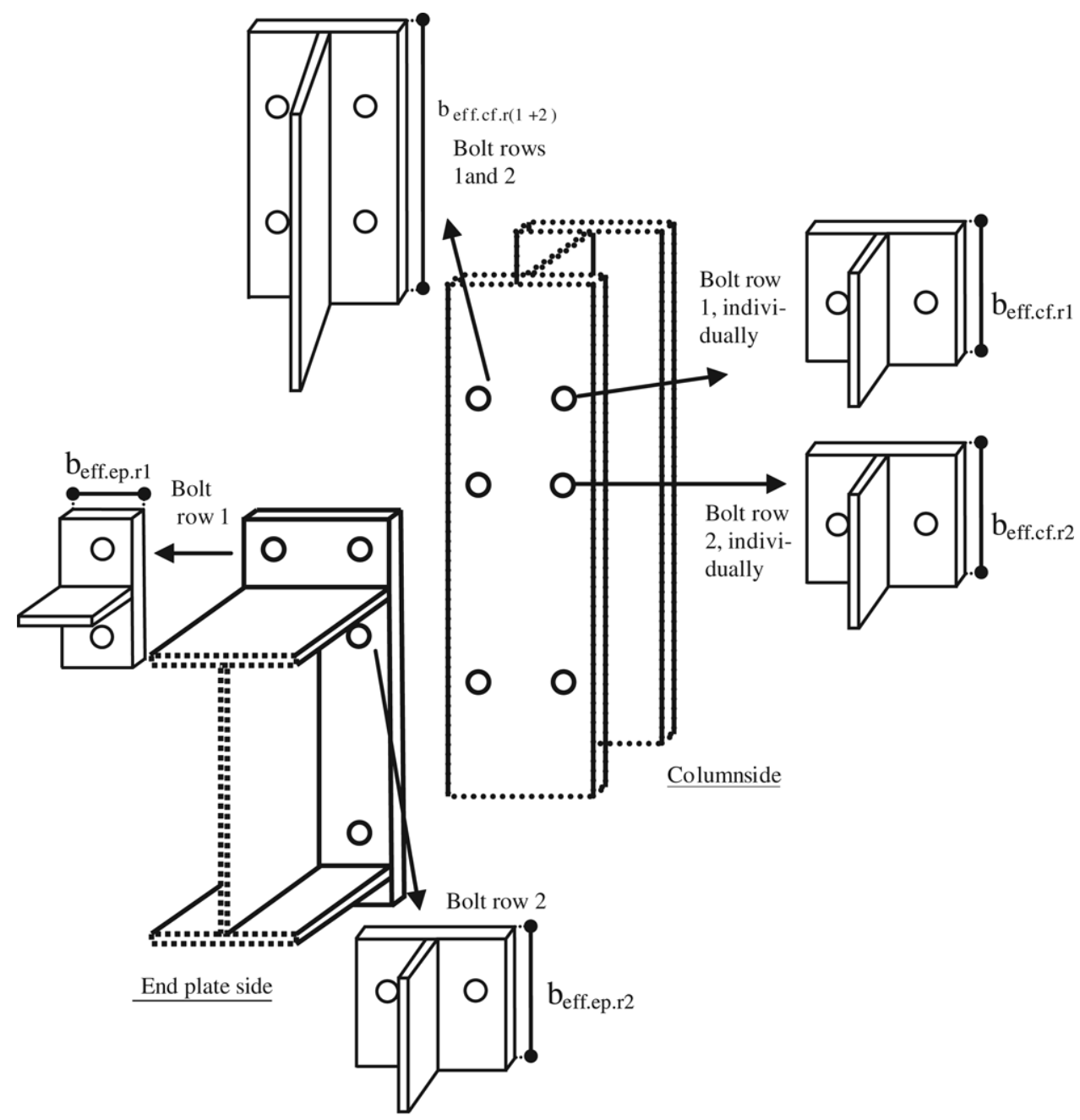

Fig. 16. T-stub idealization of an extended end plate bolted connection with two bolt rows in tension [13].

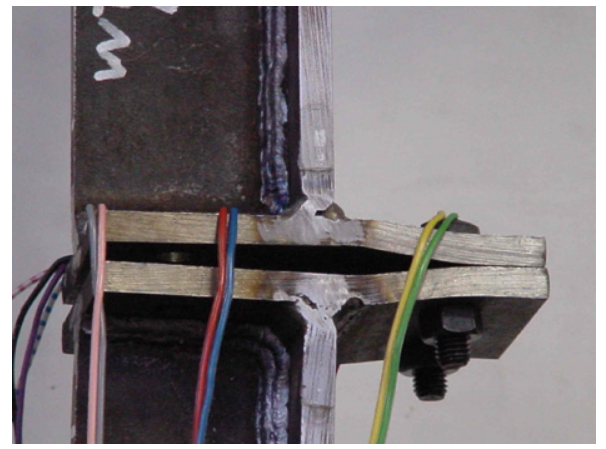

(a) Specimen WT61b (failure type-A).

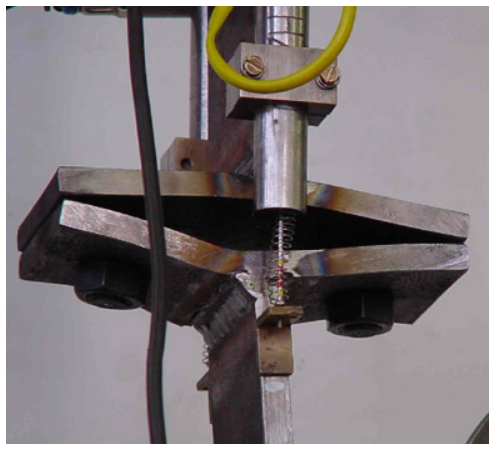

(b) Specimen WT7_M16 (failure type-C).

Fig. 17. Specimens at failure [12].

near the web, i.e. at section (A*) (Fig. 14). This section (A*) is defined at a distance $m^{*}=d-r$ or $m^{*}=d-\sqrt{2} a_{w}$ for HR-T-stubs and WP-T-stubs, respectively.

The proposed methodology was calibrated (see Fig. 19) with experimental or numerical (three-dimensional finite element model) results, showing a good agreement of results in terms of stiffness and resistance. In terms of ductility, the model predicts the deformation capacity accurately if the cracking of the flange is critical. Fig. 19 also includes the bilinear predictions from [16], for comparison.

The identification of the failure modes of the T-Stub and the associated level of deformation was the main objective of this work. Despite the extensive characterization of the behaviour of the T-Stub and the identification of the various failure modes, design procedures for the estimation of the failure modes and the levels of deformation are still not available. In addition, 


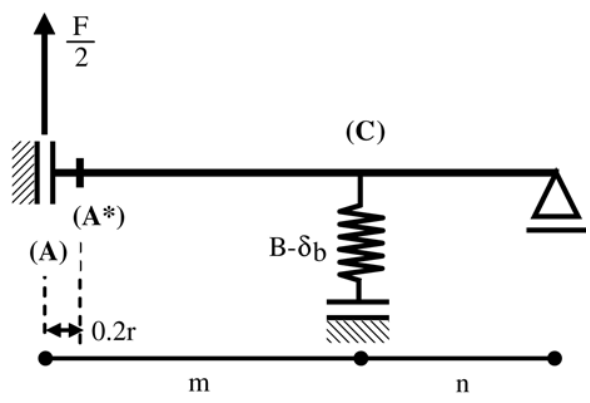

Fig. 18. Proposed T-stub model.

the T-Stub model of Fig. 18, despite its complexity, does not significantly improve on the much simpler proposal by Jaspart. Finally, the performance of the T-Stub idealization for multiple bolt rows at failure conditions still remains an open question.

\section{Extending knowledge at the joint level under static monotonic conditions: $M-N$ interaction}

Among all generalized loading conditions for steel joints, bending and axial force represent a common situation that only recently received proper attention from the research community [50]. Here, the knowledge of the behaviour of individual components is not sufficient, since interactions occur between the various components that must be assessed at the joint level. Preliminary theoretical attempts to deal with this problem were initiated at Liège [10] and Coimbra [43,44,2] but the lack of experimental evidence did not allow significant developments. To fill this gap, an experimental programme on the behaviour of steel joints under bending and axial force using endplate beamto-column joints was performed at the University of Coimbra, comprising fifteen prototypes, i.e., eight flush endplate joints and seven extended endplate joints (Fig. 20). In all tests, the joint configurations were identical, the column being simplysupported at both ends and consisting of a HEB240, the beams sections were IPE240 and the endplate was $15 \mathrm{~mm}$ thick, all manufactured from S275 steel. The bolts were M20, grade 10.9, pre-stressed with a torque of $150 \mathrm{~N} \mathrm{~m}$.

The adopted loading strategy consisted of an initial application of the total axial force (tension or compression, the loading scheme being illustrated in Figs. 21 and 22,

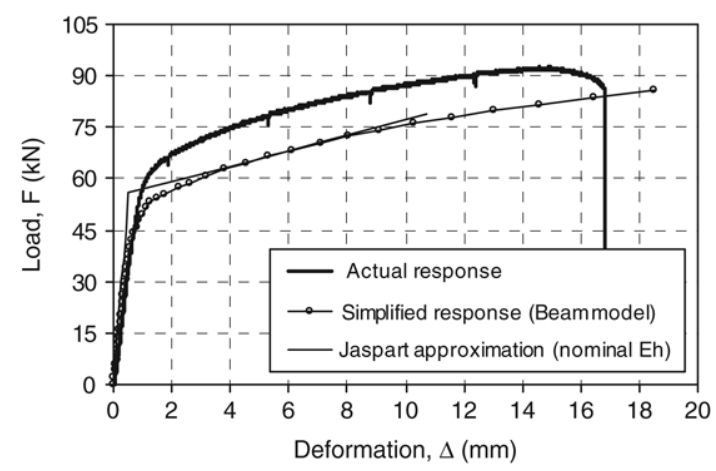

(a) Specimen WT1. respectively), kept constant during the test and the subsequent incremental application of the bending moment. For the extended end-plate joints, in the first test, EE1, only the bending moment was applied. For the following tests: EE2, EE3, EE4, EE5, EE6 and EE7 - constant axial forces of, respectively, $-10 \%,-20 \%,-27 \%,-15 \%,+10 \%$ and $+20 \%$ of the beam plastic resistance were applied to the beam. A similar strategy was used for the flush end-plate joints. The objective of this loading strategy was to identify the $M-N$ interaction curve for various levels of resistance (elastic resistance and plastic resistance), for the predominant bending situations.

Details of the testing program and instrumentation may be found in [50,27], respectively, for the flush and the extended endplate joints. The adopted instrumentation enabled the characterization of the behaviour of the joints, including the derivation of stress distributions and deformation patterns of the components.

These tests have shown that the presence of an axial force may affect significantly the joint response in terms of bending resistance. For the flush end-plate joints, for low levels of compressive axial force, an increase of the bending resistance was observed. On the other hand, the presence of tensile axial force on the joint caused immediate reduction of the bending resistance due to premature yielding of the critical joint component in the tension zone, i.e., endplate in bending. Fig. 23 shows the deformed joints for tests FE6 (compressive axial force of $27 \%$ of the beam plastic resistance) and FE9 (tensile axial force of $20 \%$ of the beam plastic resistance), respectively.

The moment-rotation curves for all tests on extended endplate joints are illustrated in Fig. 24, where the influence of the axial force on the joint behaviour is clearly noted.

Fig. 25 illustrates the experimental $M-N$ interaction diagram corresponding to: (i) the elastic resistance of the joint (taken as yielding of the first component); (ii) the plastic resistance, taken, either as (ii.1) the moment corresponding to a secant stiffness of $S_{j, \text { ini }} / 2$, or (ii.2) a secant stiffness of $S_{j, \text { ini }} / 3$ and (iii) the maximum resistance.

These tests provided experimental evidence of the relevance of considering this interaction for design purposes, even for low values of axial force in the beam. It led to the introduction of a strict restriction that the axial force be smaller than $5 \%$ of the beam plastic axial resistance to be able to

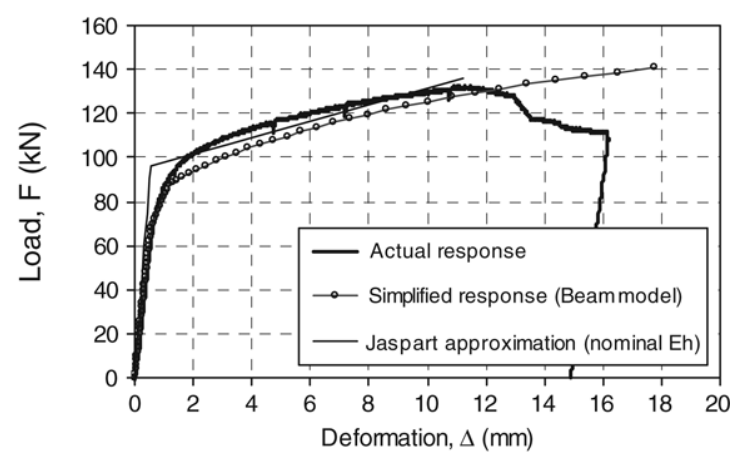

(b) Specimen WT7_M16.

Fig. 19. Prediction of the force-deformation response of some T-stub specimens [12]. 

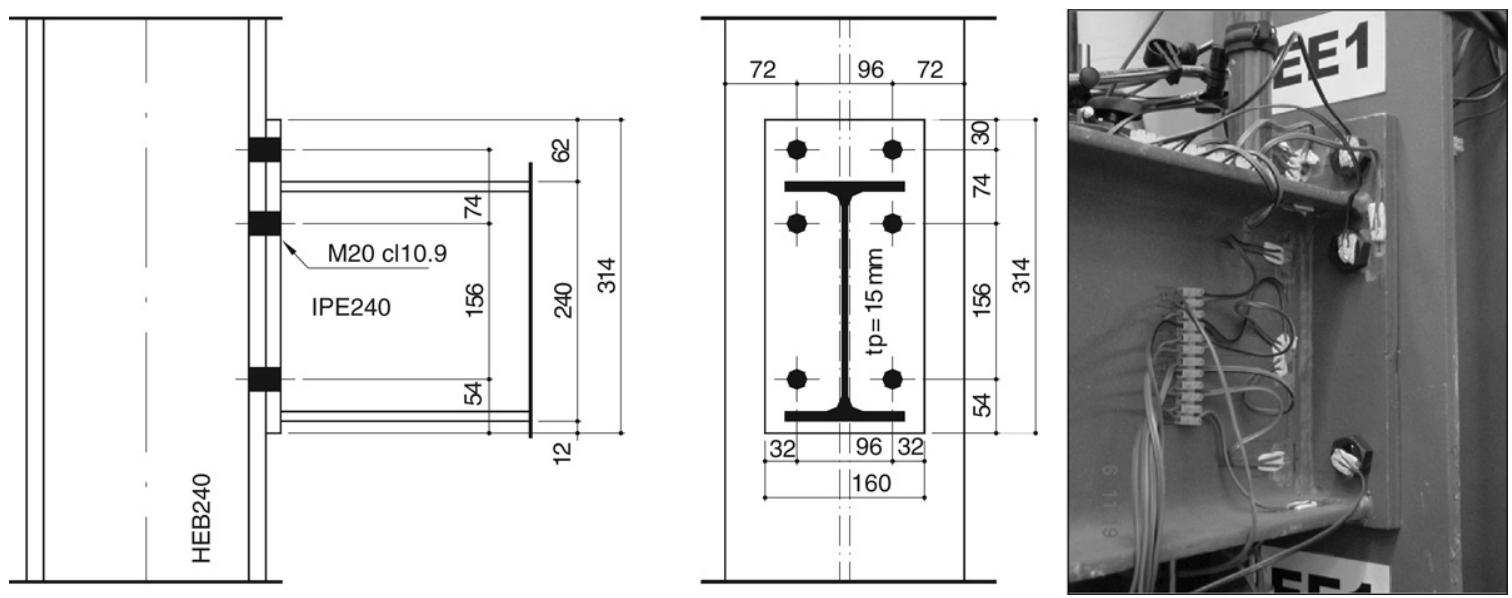

Fig. 20. Extended endplate beam-to-column joint layout [27].
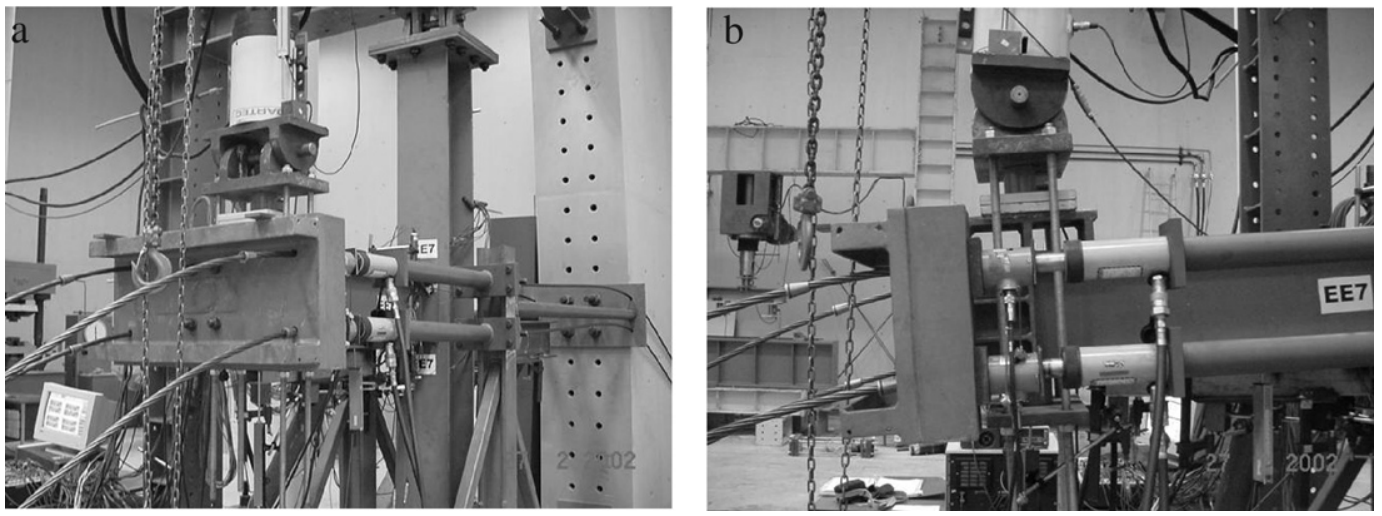

Fig. 21. (a) Tensile axial application system, (b) hydraulic jack layout [27].

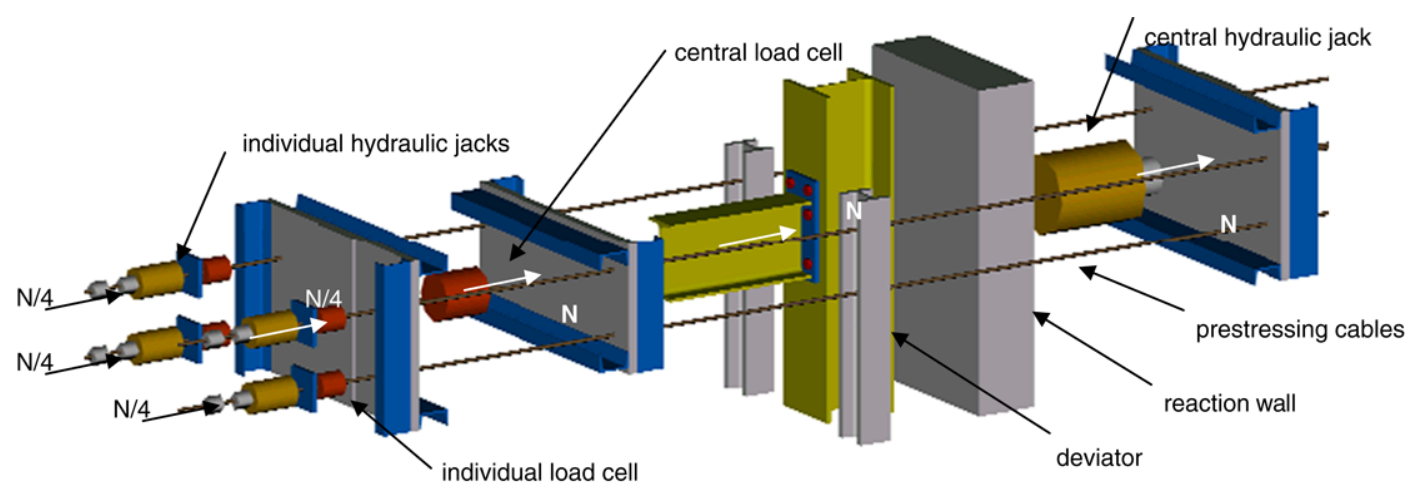

Fig. 22. Compressive axial load application system [27].

neglect the effect of the axial force on the connection. The use of component models to estimate the moment versus rotation/axial force-displacement response of beam-to-column joints subjected to bending moment and axial force is not a straightforward extension of similar models developed only for bending. Firstly, depending on the loading history, the shift of the neutral axis in the joint during loading is much more pronounced than in the pure bending case, requiring the assessment of the appropriate unloading behaviour of the joint components. Additionally, each component must present a distinct behaviour in tension and in compression. Finally, whenever multiple bolt rows are present, some additional phenomena such as stiffness coupling and group behaviour are also crucial and can modify the response of the joint. A detailed design procedure for dealing with these aspects and validated against the Coimbra tests was recently developed at Liège [5] that seems to capture all these phenomena. Subsequent work at Liège in the framework of an RFCS project [18] has further validated the Cerfontaine model in the context of composite joints and for the complete interaction diagram, including cases of predominant axial force. More recently, Savio et al. [42] have reviewed existing approaches to deal with the $M-N$ interaction and presented an alternative formulation, also validated against the Coimbra tests. It is clear that it 


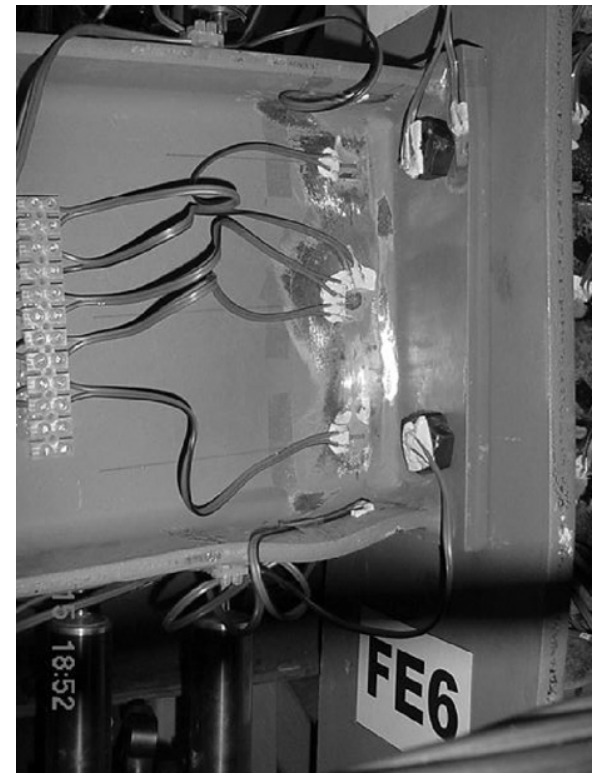

(a) Test FE6 $(N=-27 \% N p l)$ - beam flange in compression.

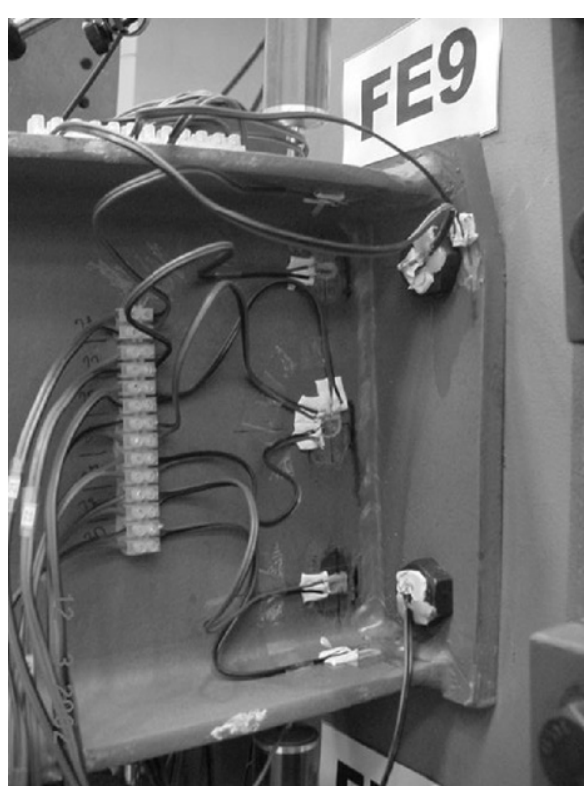

(b) Test FE9 $\left(N=+20 \% N_{p l}\right)$ - endplate in bending.

Fig. 23. Failure of flush endplate beam-to-column joints [50].

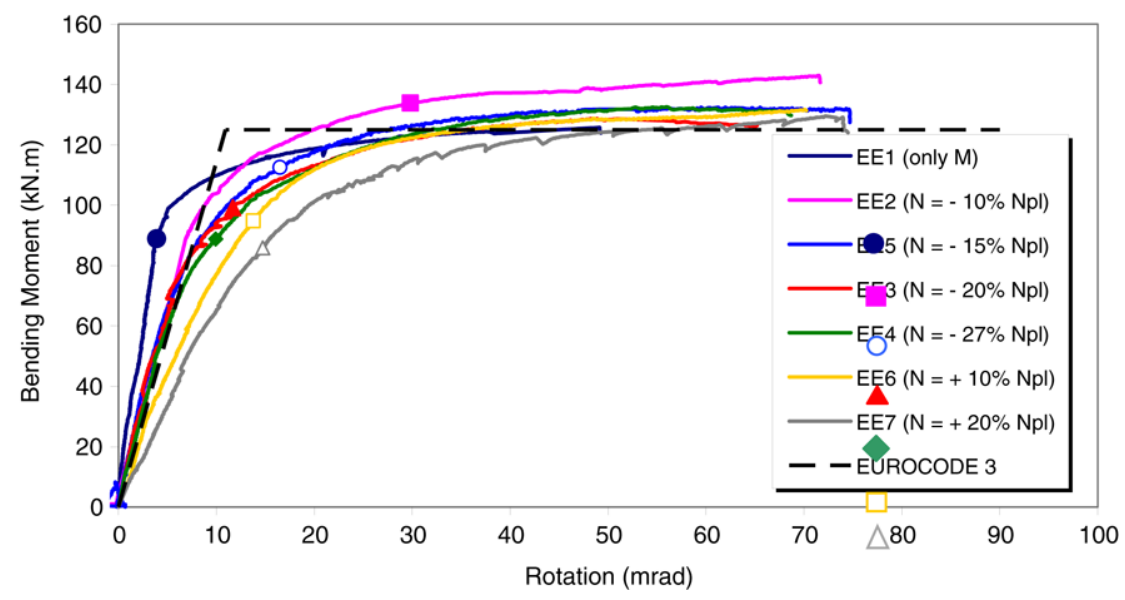

Fig. 24. Experimental tests: Moment-rotation curves.

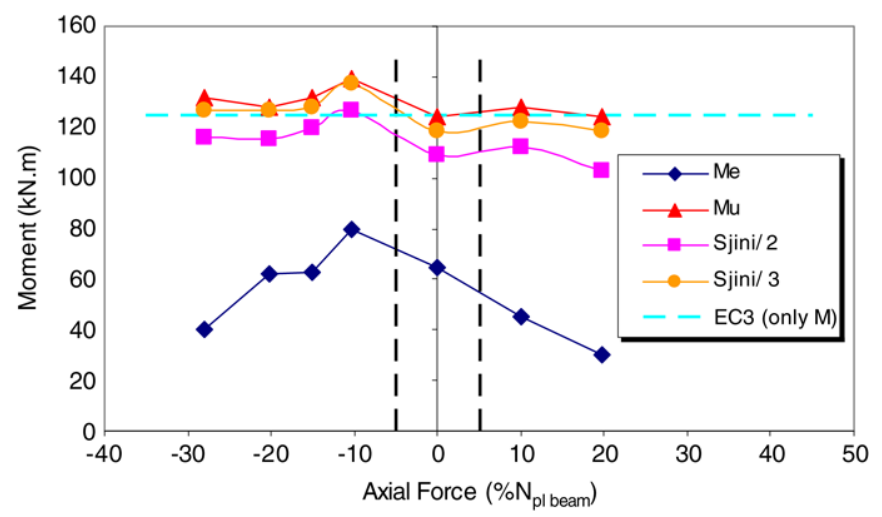

Fig. 25. $M-N$ interaction diagram.

is necessary to conceptualize and further validate a simple design procedure that ensures ductile behaviour, since the $M-N$ interaction is one of the controlling mechanisms in a wide spectrum of situations, playing, for instance, a crucial role in the behaviour of steel joints under fire loading and constituting an essential requirement to ensure robustness of steel structures.

\section{Extending knowledge under generalized loading condi- tions}

Steel structures under fire conditions probably provide the most complex transient loading conditions for steel joints. Historically, as recently as 1995, the European pre-standard on the fire response of steel structures [3] deemed it unnecessary to assess the behaviour of steel joints under fire conditions. This approach was supported by the argument of the increased bulk of the joint area. In reality, joints may fail and against common belief, during the cooling phase of natural fire, as was predicted by Santiago et al. [38] and observed during the fire test in 

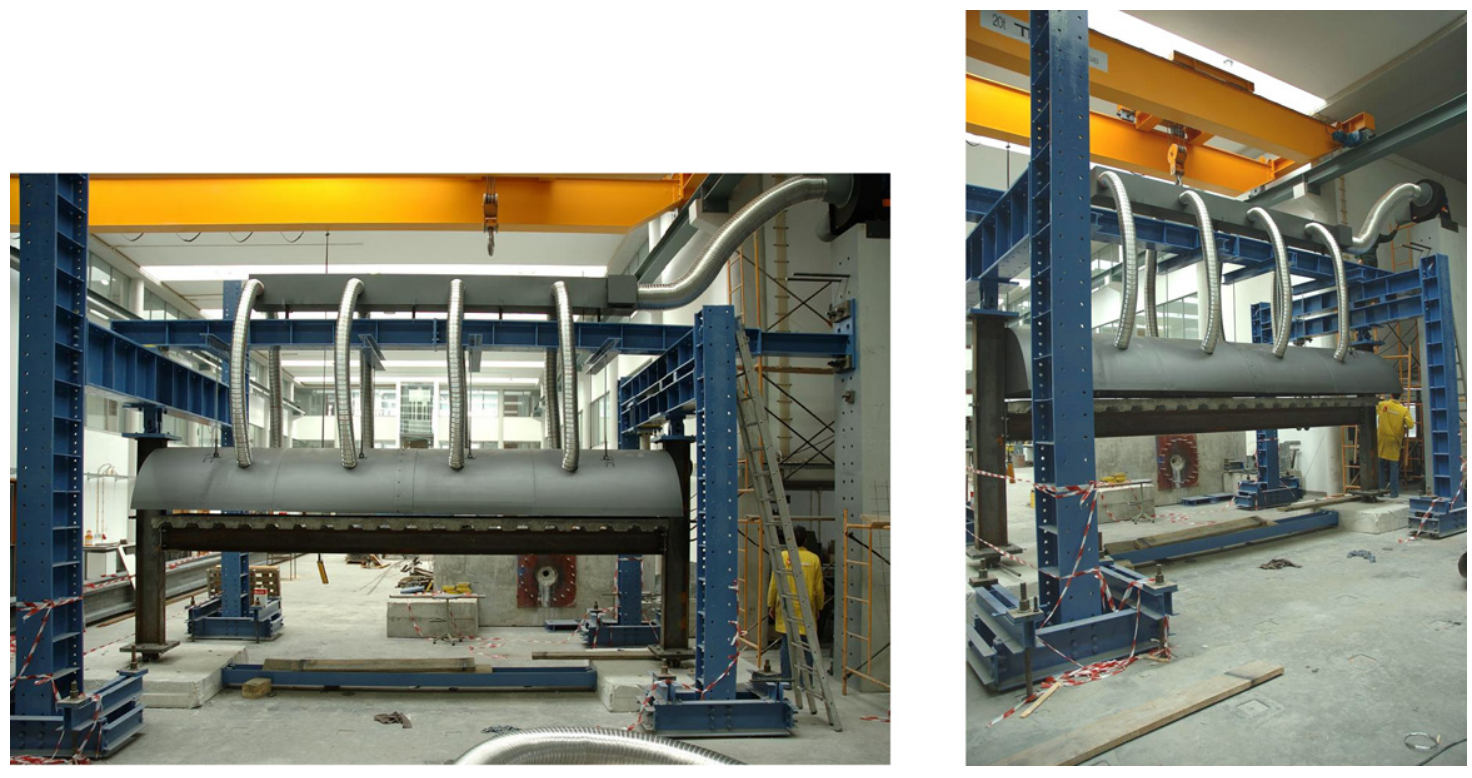

Fig. 26. General layout.

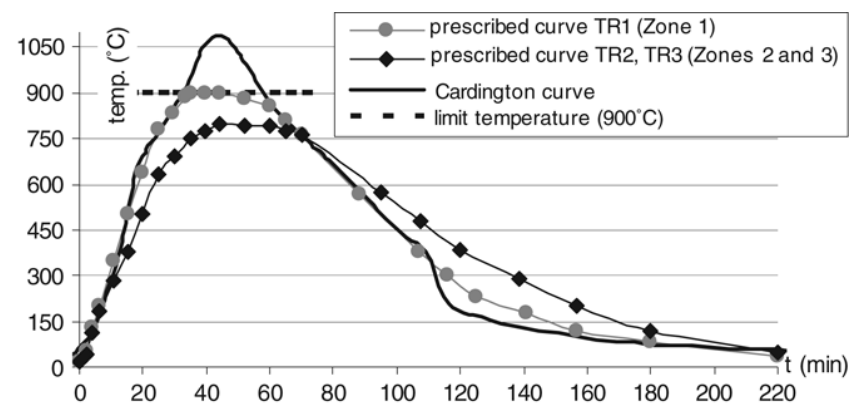

Fig. 27. Thermal loading [40].

Cardington [56]. A thorough review of the research into the fire behaviour of steel joints can be found in [51]. To address this issue, an experimental test programme was carried out at the University of Coimbra on a steel sub-frame in order to evaluate the behaviour of various types of steel joints under a natural fire and transient temperature conditions along the length of the beam. The tests were carried out on a custom developed experimental installation that could reproduce the transient temperature conditions measured in the 7 th Cardington test [57]. The results of these tests provide invaluable evidence on how to design joints that are able to survive a fire.

The experimental programme consists of the testing of a series of sub-frames composed by two thermally insulated HEA300 cross-section columns and an unprotected IPE300 cross-section beam with $5.70 \mathrm{~m}$ free span, supporting a concrete slab (Fig. 26). These dimensions were chosen to reproduce the measured dimensions of a steel sub-frame from the fire compartment of the 7th Cardington fire test [56]. Most importantly, the testing of a full-scale sub-frame composed of a beam and two columns allowed the reproduction of the redistribution of forces that takes place in a real (statically indeterminate) structure, including the effect of the axial and rotational restraint from the columns. Details of the testing program and instrumentation may be found in [39]. The adopted instrumentation enabled the characterization of the behaviour of the sub-fame, including the characterization of time-temperature curves and the structural response of the joints.

The experimental programme comprised six tests and the varied parameter was the beam-to-column connection configuration (Table 2). They were representative of the usual joint typologies used in building frames: header plate; flush and extended end-plate and welded.

The mechanical loading was applied at two points of the beam top flange, $700 \mathrm{~mm}$ to either side of the beam midspan, corresponding to a load ratio of 0.2 . Thermal loading was applied to the beam and joints (from the beam side only), while the columns were thermally protected. Thermal loading was time dependent (heating and cooling phases) and was also variable along the beam span (Fig. 27). The beam temperature-time curves applied at each beam zone reproduced the values measured in a previous full-scale test [56,57] and they correspond to the measured temperatures at the beam bottom flange.

Fig. 28 compares the temperature curves for the various connection elements of joints in zone Z3 (test EJ01). In the heating phase, the connection temperature was significantly lower than the remote bottom flange at mid-span; in contrast, the cooling down in the joint elements was slower, because of: (i) shielding by the adjacent cold column; (ii) concentration of mass in the connection elements; and, (iii) the different prescribed thermal loading applied at the joints section. The maximum temperature at the connection is thus reached during the cooling phase.

Fig. 29 compares the evolution of the mid-span deflections during the fire. In the case of the FJ02, EJ01 and WJ01 tests, a maximum deflection of $375 \mathrm{~mm}$ was approximately reached (these values were measured already during the cooling phase). For the PJ01 test, Z3 joint collapsed during the heating phase of the fire $\left(\theta_{0}=900^{\circ} \mathrm{C}\right)$ as a result of the run-way deflection at high temperatures $\left(\delta_{\text {beam }}=393 \mathrm{~mm}\right)$. During cooling, the 
Table 2

Test programme

\begin{tabular}{|c|c|c|c|}
\hline Test ID & Joint typology & End-plate dimensions $(\mathrm{mm})$ and steel grade & Bolts / Weld ( $a_{f}, a_{w}$, weld throat thickness, mm) \\
\hline FJ01 & & $(320 \times 200 \times 10) ; \mathrm{S} 275$ & 2 bolt row M20, 8.8 \\
\hline FJ02 & Flush end-plate & $(320 \times 200 \times 16) ; S 275$ & 2 bolt row M20, 10.9 \\
\hline FJ03 & & $(320 \times 200 \times 16) ; \mathrm{S} 275$ & 2 bolt row $\mathrm{M} 20,8.8$ \\
\hline EJ01 & Extended end-plate & $(385 \times 200 \times 16) ; \mathrm{S} 275$ & 3 bolt row M20, 8.8 \\
\hline HJ01 & Header plate & $(260 \times 150 \times 8) ; S 275$ & 4 bolt row M20, 8.8 \\
\hline WJ01 & Welded joint & - & $a_{f}=a_{w}=10$ \\
\hline
\end{tabular}

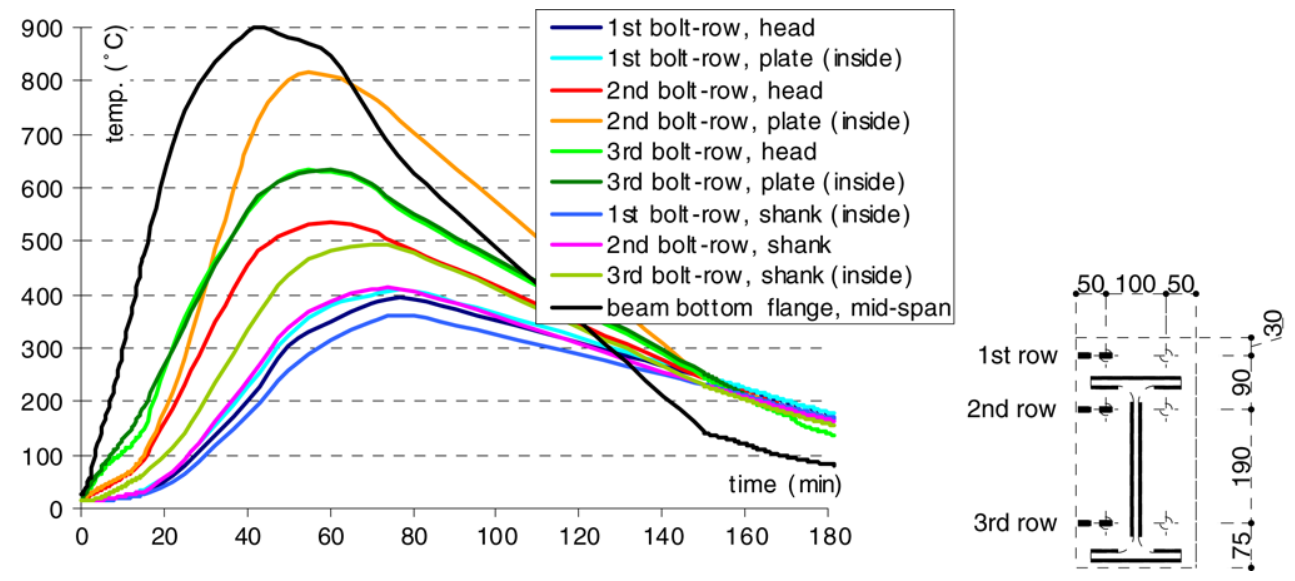

Fig. 28. Temperature within the joint Z3 (test EJ01).

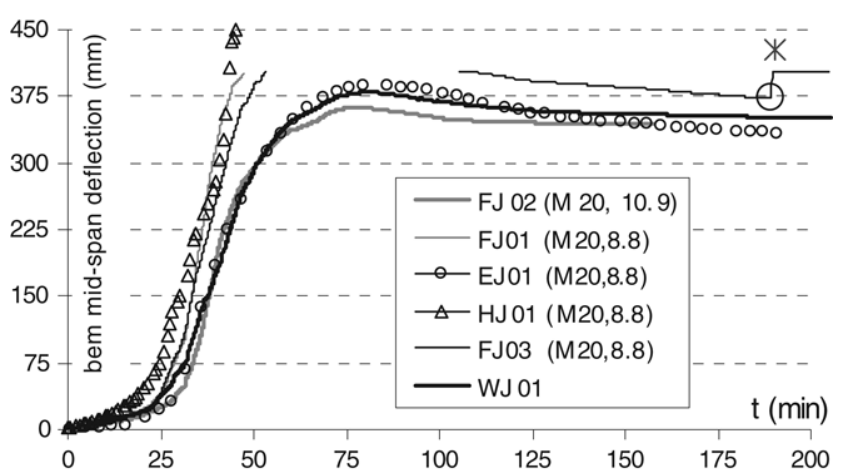

Fig. 29. Mid-span deflection of the beams.

heated beams began to recover strength and stiffness from an inelastic state, together with a reduction of thermal strains. This induced tensile axial forces and the reversal of the deflection. For test FJ01 a maximum deflection of $428 \mathrm{~mm}$ was measured at the end of the fire.

For test FJ03, failure of the bottom bolt-row at $t=190 \mathrm{~min}$ after the beginning of the fire; the top bolt-row fractured later ( $t=382$ min). Fig. 30 shows the deformed structure at the end of the FJ01 test.

These tests evidenced a clear influence of the joint typologies on the overall response of the sub-frame. They demonstrated the appearance of large tensile forces and the reversal of joint rotation during the cooling phase that, depending of the joint typology, may result in failure of their tensile components. Numerical simulations were carried out using the finite element programme LUSAS. The typical overall

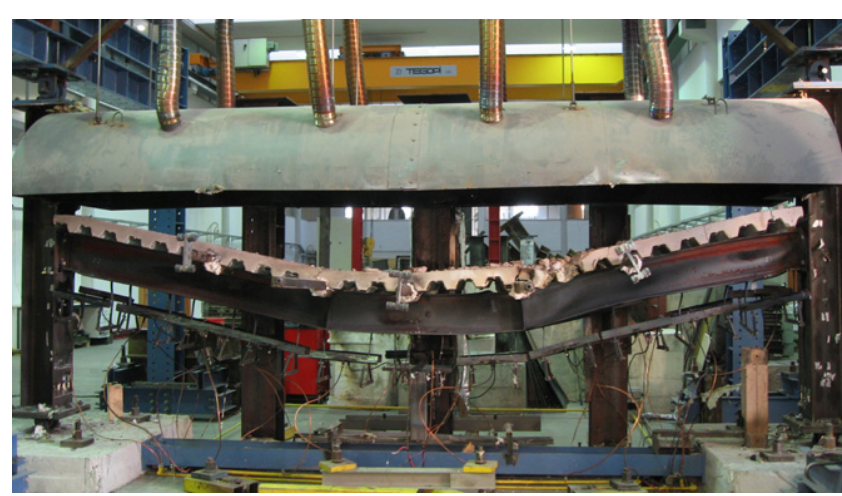

Fig. 30. Deformed structure after test FJ01.

failure mode for FJ03 is shown in Fig. 31, comparing the FE and the experimental failure modes: local buckling in the bottom flange and web, end-plate deformation (on the top during the heating phase and on the bottom during the cooling) and large principal strains on the 2 nd bolt-row are only noticeable during the cooling phase (Fig. 32(a)).

The numerical study allowed the evaluation of the performance of each individual structural joint component, as well as the identification of the main dependencies of the geometrical and mechanical variables of the components on the global joint behaviour.

From the experimental and numerical results it was possible to develop analytical procedures for the calculation of the behaviour of beam-to column steel joints. Based on the component approach presented in [45], updated to incorporate 

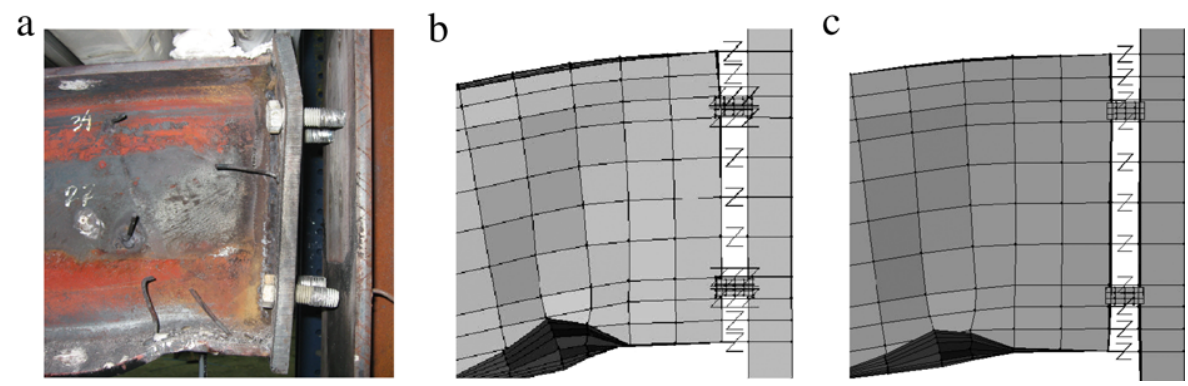

Fig. 31. Failure mode for FJ03: (a) experimental test; (b) FE analysis (heating phase); (c) FE analysis (cooling phase); (scale factor: x1).
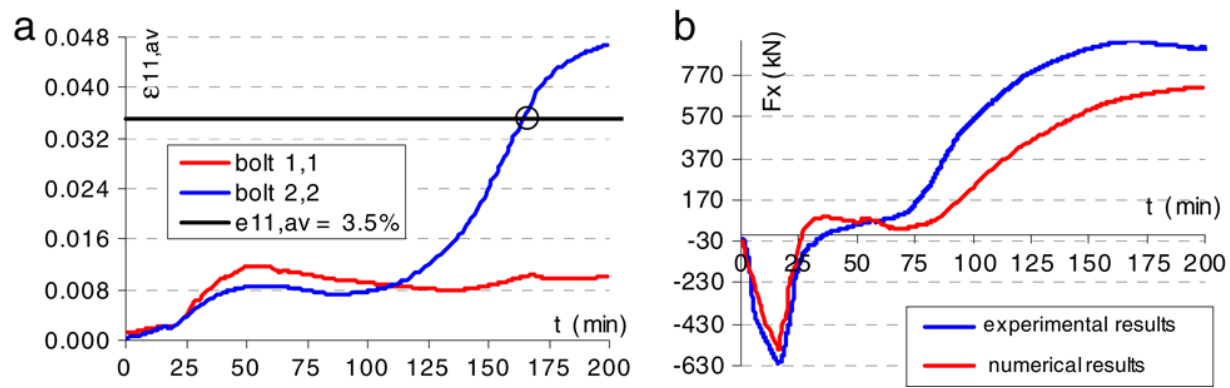

Fig. 32. (a) Averaged principal strains at the bolts; (b) FE and experimental reaction axial force.
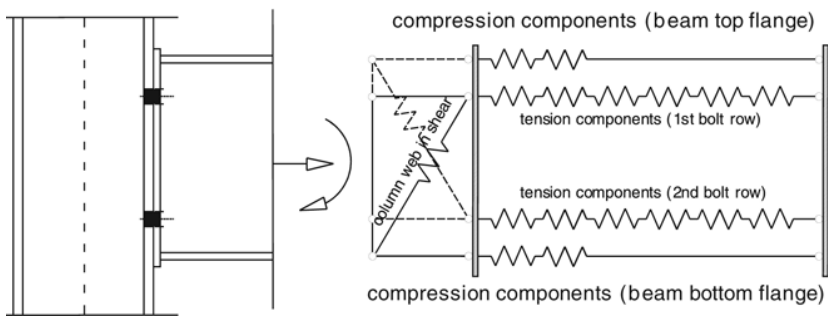

compression components (beam bottom flange)

Fig. 33. Component model for flush end-plate joint.

additional relevant features [41], the following model can be proposed to model a flush end-plate joint (Fig. 33).

This component-based methodology is able to reproduce with sufficient accuracy the transient response of the steel joints throughout the fire development and to identify the failure modes of the joint. This procedure provides an adequate basis for its incorporation in advanced calculation methods through the development of specialized joint finite elements.

In general terms, these developments agree well with the observed experimental behaviour. However, much work remains to be done, in particular to ensure a wide applicability of this methodology. Finally, for conceptual and pre-design, the proposal of simple design recommendations for the survival of joints subjected to fire remains a desirable goal.

\section{Concluding remarks}

The paper presented a conceptual model based on the component method for the consistent $3 \mathrm{D}$ design of joints. By adhering to the principles of the component method (using basic components and, as much as possible, taking into consideration the interactions between the deformation of the various components in a diagonalized way), this conceptual model allows the combination, as is, of the existing component models for the range of situations validated by experimental evidence with new additional component models derived from experimental work thus expanding the design procedures for steel joints to situations still not covered in detail by the codes of practice.

The experimental research projects described in this paper were designed to expand the range of applicability of the component method and provided a wealth of information for the calibration of some of the generalized stiffness coefficients of expressions (1)-(4), a task that is currently being actively pursued at the University of Coimbra.

Many issues still remain open with respect to the behaviour of steel joints. Without attemting to be systematic, the following topics are worth mentioning: (i) development of design procedures for joints subjected to seismic action; (ii) validation of the design concepts of the component method for large scale joints such as bolted joints in bridges; (iii) development of design procedures for high-performance joints between circular hollow section columns and I-beams; and (iv) practical joints for the connection of steel and concrete members.

\section{Acknowledgements}

Financial support from the Portuguese Ministry of Science and Higher Education (Ministério da Ciência e Ensino Superior) under contract grant PTDC/ECM/64217/2006 is gratefully acknowledged.

\section{References}

[1] Bayo E, Cabrero JM, Gil B. An effective component-based method to model semi-rigid connections for the global analysis of steel and composite structures. Engineering Structures 2006;28:97-108. 
[2] Borges LAC. Probabilistic evaluation of the rotation capacity of steel joints. M.Sc. thesis. Coimbra: Universidade de Coimbra; 2003.

[3] CEN, Eurocode 3: Design of steel structures, Part 1.2: Structural fire design. ENV-1993-1-2. Brussels: European Committee for Standardization; 1995.

[4] CEN, Eurocode 3: Design of steel structures, Part 1.8: Design of joints. EN-1993-1-8. Brussels: European Committee for Standardization; 2005.

[5] Cerfontaine F. Bending moment and axial force interaction in bolted joints. Ph.D. thesis. Université de Liège; 2003.

[6] Chen WF, Lui EM. Static web moment connections. Journal of Constructional Steel Research 1988;10:89-131.

[7] Cruz PJS, Simões da Silva L, Rodrigues DS, Simões RAD. Database for the semi-rigid behaviour of beam-to-column connections in seismic regions. Journal of Constructional Steel Research 1998;46(120):1-3.

[8] Davison JB, Kirby PA, Nethercot DA. Rotational stiffness characteristics of steel beam-column connections. Journal of Constructional Steel Research 1987;8:17-54.

[9] Dutta D, Wardenier J, Yeomans N, Sakae K, Bucak O, Packer J. Guide de dimensionnement pour la fabrication, l'assemblage et le montage des structures en profils creux. Série CIDECT "Construire avec des profiles creux" public, vol. 7. Colónia: Verlag TUV Rheinland; 1999.

[10] Finet L. Influence de l'effort normal sur le calcul des assemblages semirigides. CUST. Clermont Ferrand: Université Blaise Pascal - Université de Liège; 1994.

[11] France JE. Bolted connections between open section beams and box columns. Ph.D. thesis. University of Sheffield; 1997.

[12] Girão A, Bijlaard F, Gresnigt N, Simões da Silva L. Experimental assessment of the behaviour of bolted T-stub connections made up of welded plates. Journal of Constructional Steel Research 2004;60: 269-311.

[13] Girão A, Simões da Silva L, Bijlaard F. Ductility analysis of bolted extended end-plate beam-to-column connections in the framework of the component method. International Journal of Steel and Composite Structures 2006;6(1):33-53.

[14] Gomes FCT, Jaspart JP, Maquoi R. Moment capacity of beam-to-column minor-axis joints. In: Proceedings of the IABSE international colloquium on semi-rigid structural connections. Istanbul (Turkey): IABSE; 1996. p. 319-26.

[15] Janss J, Jaspart JP, Maquoi R. Strength and behaviour of in plane weak axis joints and 3D joints. In: Proc. of the state of the art workshop on connections and the behaviour, strength and design of steel structures. 1987. p. 60-8.

[16] Jaspart JP. Etude de la semi-rigidité des noeuds poutre-colonne et son influence sur la resistance et la stabilité des ossatures en acier. Ph.D. thesis. Liège: University of Liège; 1991 [in French].

[17] Jaspart J-P. Contributions to recent advances in the field of steel joints column bases and further configurations for beam-to-column joints and beam splices. Aggregation thesis. Université de Liège; 1997.

[18] Jaspart J-P, Demonceau J-F. Contribution to the derivation of robustness requirements for steel and composite structures. In: ICASS07 - 5th International conference on advances in steel structures. Singapore: National University of Singapore and Singapore Structural Steel Society; 2007.

[19] Jordão S, Simões da Silva L, Simões R. Numerical evaluation of the response of the column web panel under asymmetrical patch loading. In: Topping BHV, editor. Proceedings of 7th international conference on computational structures technology. Stirling (United Kingdom): CivilComp Press; 2004.

[20] Jordão S, Simões da Silva L, Simões R. Experimental characterisation of the column web panel in an internal node beam-to-column welded joint with beams of unequal height. In: Proceedings of the international conference "steel a new and traditional material for building". 2006.

[21] Jordão S, Simões da Silva L, Simões R. Experimental behaviour of internal joints with beams of different heights, steel grade S690. In: Beale, editor. Proceedings of ICSAS'07. 2007.

[22] Jordão S, Simões da Silva L, Simões R. Design rules proposal for high strength steel: Internal nodes with beams of different heights. Eurosteel 2008 - 5th European conference on steel and composite structures. 2008.
[23] Kim YW. The behaviour of beam-to-column web connections with flush end plates. M.Sc. thesis. University of Warwick; 1988.

[24] Kosteski N, Packer JA. Welded Tee-to-HSS connections. Journal of Structural Engineering 2003;129(2):151-9.

[25] Krawinkler H, Bertero VV, Popov EP. Inelastic behavior of steel beam-to-column subassemblages. Report UCB/EERC-71/7. Earthquake Engineering Research Center, University of California Bekerley; 1971.

[26] Kuhlmann U, Kühnemund F. Proposal of a new design resistance of the joint component column web in compression. Report 2001-7x. Institut für Konstruktion und Entwurf Universität Stuttgart; 2001.

[27] Lima L, Simões da Silva L, Vellasco P, Andrade S. Experimental behaviour of extended end-plate beam-to-column joints subjected to bending and axial force. Engineering Structures 2004;26(10):1333-47.

[28] Lu LH, Puthli RS, Wardenier J. Semi-rigid connections between plates and rectangular hollow section columns. In: Proceedings of the fifth international symposium on tubular connections held at Nottingham. London: E \& FN Spon; 1993. p. 723-31.

[29] Lu LH, Wardenier J. The ultimate strength of I-beam to RHS column connections. Journal of Constructional Steel Research 1998;46(139):1-3.

[30] Maquoi R, Jaspart JP, Guisse S, Lognard B, Taquet F. Etude expérimentale et théorique du comportement des noeuds poutre-colonne d'axe faible. Sixième rapport semestriel. Recherche COST C1 Région Wallonne - Université de Liège; 1995.

[31] Mourad S, Korol R, Ghobarah A. Design of extended end-plate connections for hollow section columns. Canadian Journal of Civil Engineering 1996;23:277-86.

[32] Neves LFC. Nós Semi-Rígidos em Estruturas Metálicas - Avaliação da Rigidez em Configurações de Eixo Fraco. M.Sc. thesis. Coimbra: Universidade de Coimbra. FCTUC; 1996 [in Portuguese].

[33] Neves L, Simões da Silva L, Vellasco P. Behaviour of end-plate minoraxis beam-to-column joints under monotonic loading. In: Lamas A, Simões da Silva L, editors. Proceedings of Eurosteel 2002 - 3rd European conference on steel structures. 2002. p. 1101-10.

[34] Neves L, Simões da Silva L, Vellasco P. Experimental behaviour of end plate I-beam to concrete-filled rectangular hollow section column joints. International Journal of Applied Mechanics and Engineering 2004;9(1): 63-80.

[35] Neves L, Simões da Silva L, P Vellasco. A model for predicting the stiffness of beam to concrete filled column and minor axis joints under static monotonic loading. In: Hoffmeister B, Hechler O, editors. Eurosteel 2005 - 4th European conference on steel and composite structures research - Eurocodes - practice. Druck und Verlagshaus Mainz GmbH. Aachen. vol. C. 2005. p. 4.10.131-38.

[36] Packer J, Morris G, Davies G. A limit states design method for welded tension connections to I-section webs. Journal of Constructional Steel Research 1984;12:33-53.

[37] Rentschler GP, Chen WF, Driscoll GC. Beam to column web connection details. Journal of the Structural Division, ASCE 1982;108:393-409. no ST2.

[38] Santiago A, Simões da Silva L, Vila Real P, Franssen JM. Effect of cooling on the behaviour of a steel beam under fire loading including the end joint response. In: Topping BHV, editor. Proceedings of 9th international conference on civil and structural engineering computing. Stirling (United Kingdom): Civil-Comp Press; 2003. paper 65.

[39] Santiago A, Simões da Silva L, Vila Real P. Experimental investigation of the behaviour of a steel sub-frame under a natural fire. In: Proceedings of ICSCS'07. 2007.

[40] Santiago A, Simões da Silva L, Vila Real P. Recommendations for the design of end-plate beam-to-column steel joints subjected to a natural fire. In: Eurosteel 2008 - 5th European conference on steel and composite structures. 2008.

[41] Santiago A. Behaviour of beam-to-column steel joints under natural fire. Ph.D. thesis. Coimbra: University of Coimbra; 2008.

[42] Savio A, Nethercot D, Vellasco P, Andrade S, Martha LF. A component method model for semi-rigid end-plate beam-to-column joints including the axial versus bending moment interaction. In: ICASS07 - 5th International conference on advances in steel structures. Singapore: National University of Singapore and Singapore Structural Steel Society; 2007. 
[43] Simões da Silva L, Coelho A. A ductility model for steel connections. Journal of Constructional Steel Research 2001;57(1):45-70.

[44] Simões da Silva L, Coelho A. Analytical evaluation of the response of steel joints under bending and axial force. Computers \& Structures 2001; 79:873-81.

[45] Simões da Silva L, Santiago A, Vila Real P. A component model for the behaviour of steel joints at elevated temperatures. Journal of Constructional Steel Research 2001;57(11):1169-95.

[46] Simões da Silva L, Calado L, Simões R, Girão A. Evaluation of ductility in steel and composite beam-to-column joints: Analytical evaluation. In: Leon R, Easterling WS, editors. Connections in steel structures iv: Steel connections in the new millenium. USA: AISC; 2002. p. 223-32.

[47] Simões da Silva L, Santiago A, Vila Real P. Post-limit stiffness evaluation of the ductility of steel joints. Computers \& Structures 2002;80:515-31.

[48] Simões da Silva L, Neves L, Baniotopoulos L, Perdikaris P, Zygomalas Bouchair H, Bosiljkov V, et al. Evaluation of structural robustness of members and connections. In: Simões da Silva L, Mendes J, editors. Proceedings of the COST C12 seminar on improvement of structural building's quality by new technologies. Brussels: European Comission; 2003. p. $155-74$

[49] Simões da Silva L, Neves LFC, Gomes FCT. Rotational stiffness of RHS composite connections. ASCE Journal of Structural Engineering 2003; 129(4):487-94.

[50] Simões da Silva L, Lima L, Vellasco P, Andrade S. Behaviour of flush end-plate beam-to-column joints subjected to bending and axial force. International Journal of Steel and Composite Structures 2004;4(2):77-94.

[51] Simões da Silva L, Santiago A, Vila Real P, Moore D. Behaviour of steel joints under fire loading. International Journal of Steel and Composite
Structures 2005;5(6):485-513.

[52] Simões da Silva L, Gervásio H. Manual de dimensionamento de estruturas metálicas: métodos avançados. Coimbra: cmm Press; 2007.

[53] Simões da Silva L, Jordão S, Simões R. Numerical behaviour of internal joints with beams of different heights. In: ICASS07 - 5th International conference on advances in steel structures. Singapore: National University of Singapore and Singapore Structural Steel Society; 2007.

[54] Swanson JA. Characterization of the strength, stiffness and ductility behavior of T-stub connections. Ph.D. dissertation. Atlanta (USA): Georgia Institute of Technology; 1999.

[55] Vandegans D. Liaison entre poutres métalliques et colonnes en profils creux remplis de béton, basée sur la technique du goujonnage (goujons filetés). CRIF MT 193. Bruxelles; 1995.

[56] Wald F, Simões da Silva L, Moore D, Lennon T, Chladna M, Santiago A, et al. Experimental behaviour of a steel structure under natural fire. Fire Safety Journal 2006;41(7):509-22.

[57] Wald F, Chladná M, Moore D, Santiago A, Lennon T. Temperature distribution in a full-scale steel framed building subject to a natural fire. International Journal of Steel and Composite Structures 2006;6(2): $159-82$.

[58] Weynand K, Jaspart JP, Steenhuis M. The stiffness model of revised annex $\mathrm{J}$ of Eurocode 3. In: Bjorhovde R, Colson A, Zandonini R, editors. Connections in steel structures III. Proceedings of the 3rd International workshop on connections. 1995. p. 441-52.

[59] Young CR, Jackson KB. The relative rigidity of welded and riveted connections. Canadian Journal of Research 1934;11(1-2):62-134.

[60] Zoetemeijer P. A design method for the tension side of statically loaded bolted beam-to-column connections. Heron 1974;20(1):1-59. 